\title{
Predictability of a Mediterranean Tropical-Like Storm Downstream of the Extratropical Transition of Hurricane Helene (2006)
}

\author{
Florian P. Pantillon, Jean-Pierre Chaboureau, and Patrick J. Mascart \\ Laboratoire d'Aérologie, Université de Toulouse and CNRS, Toulouse, France
}

CHRISTINE LAC

CNRM-GAME, Météo-France and CNRS, Toulouse, France

(Manuscript received 31 May 2012, in final form 30 October 2012)

\begin{abstract}
The extratropical transition (ET) of a tropical cyclone is known as a source of forecast uncertainty that can propagate far downstream. The present study focuses on the predictability of a Mediterranean tropical-like storm (Medicane) on 26 September 2006 downstream of the ET of Hurricane Helene from 22 to 25 September. While the development of the Medicane was missed in the deterministic forecasts from the European Centre for Medium-Range Weather Forecasts (ECMWF) initialized before and during ET, it was contained in the ECMWF ensemble forecasts in more than $10 \%$ of the 50 members up to 108 -h lead time. The 200 ensemble members initialized at 0000 UTC from 20 to 23 September were clustered into two nearly equiprobable scenarios after the synoptic situation over the Mediterranean. In the first and verifying scenario, Helene was steered northeastward by an upstream trough during ET and contributed to the building of a downstream ridge. A trough elongated farther downstream toward Italy and enabled the development of the Medicane in 9 of 102 members. In the second and nonverifying scenario, Helene turned southeastward during ET and the downstream ridge building was reduced. A large-scale low over the British Isles dominated the circulation in Europe and only 1 of 98 members forecasted the Medicane. The two scenarios resulted from a different phasing between Helene and the upstream trough. Sensitivity experiments performed with the Méso-NH model further revealed that initial perturbations targeted on Helene and the upstream trough were sufficient in forecasting the warm-core Medicane at 84- and 108-h lead time.
\end{abstract}

\section{Introduction}

An extratropical transition (ET) describes the process by which a tropical cyclone enters the midlatitudes and transforms into an extratropical cyclone. It is known as a challenge for numerical weather prediction (Jones et al. 2003). The process involves strong diabatic effects during interactions between synoptic and mesoscale structures, which make the forecast of the track and intensity of the transitioning cyclone difficult. In addition, an ET is a source of uncertainty in the forecast of the downstream circulation.

An ensemble prediction system (EPS) is a useful tool to study the predictability of an ET. Whereas a

Corresponding author address: Florian Pantillon, Laboratoire d'Aérologie, Observatoire Midi-Pyrénées, 14 avenue Edouard Belin, 31400 Toulouse, France.

E-mail: florian.pantillon@aero.obs-mip.fr deterministic forecast suffers from uncertainty in its initial conditions and model physics, an ensemble forecast provides a means of quantifying a portion of the uncertainty through the perturbation of initial conditions. The spread among ensemble members gives an indication of the reliability to the deterministic forecast, while the average of ensemble members often better matches observations than a single deterministic forecast (Leutbecher and Palmer 2008). Recently, a recurrent large spread associated with the transitioning cyclone has been shown in an EPS during case studies of ET on the western North Pacific and North Atlantic Oceans (Harr et al. 2008; Anwender et al. 2008; Keller et al. 2011). The spread indicates a loss of predictability, which can propagate far downstream from the ET event.

Furthermore, the application of a clustering method to an EPS has revealed the existence of multiple forecast scenarios for a given ET (Harr et al. 2008; Anwender 
et al. 2008; Keller et al. 2011). These scenarios are linked to the interaction between the transitioning cyclone and an upstream trough, often involved during ET (Harr and Elsberry 2000). They lead to different evolutions of both the cyclone and the midlatitude circulation. When the cyclone properly phases with the upstream trough, it reintensifies and its outflow accelerates a jet streak downstream (Klein et al. 2002). This impact of the cyclone outflow contributes to the building of a downstream ridge and propagates with the deepening and elongation of a trough farther downstream (Riemer and Jones 2010). A strong elongation of the downstream trough is likely to trigger explosive surface cyclogenesis (e.g., Martius et al. 2008). When the cyclone does not properly phase with the upstream trough, it rather dissipates and does not impact the midlatitude circulation (Klein et al. 2002). The clustering of ensemble members, therefore, links the evolution of the cyclone and of the downstream circulation (Anwender et al. 2008).

The use of an EPS allows identification of the origin of forecast uncertainty during ET. Uncertainties have been shown to originate from both the cyclone outflow and the upstream trough during several ETs in EPSs initialized with singular vectors (Reynolds et al. 2009; Anwender et al. 2010; Lang et al. 2012). These uncertainties grow in both the tropical cyclone and the downstream ridge. The sensitivity of the cyclone MSLP to initial conditions in both the cyclone and the upstream trough has been confirmed for two cases of ET in a shorter-term EPS initialized with an ensemble Kalman filter (Torn and Hakim 2009). In the same EPS, the origin of uncertainties in the downstream ridge has further been attributed to both the cyclone outflow and the frontal precipitation resulting from the interaction between the cyclone and the midlatitudes (Torn 2010).

An EPS is also an essential tool to forecast highimpact weather events. While deterministic forecasts often miss such events at midrange, ensemble forecasts offer a diversity of scenarios that is more likely to include them. The development of an extreme event in a few ensemble members might alert a forecaster of its possible existence. Its persistence at different initialization times further informs a forecaster about its probability of occurrence. Some extreme events that were missed by deterministic forecasts have been shown to be included in an operational EPS (Buizza and Hollingsworth 2002; Buizza and Chessa 2002). No study so far has investigated the occurrence of a particular high-impact weather event in an EPS downstream of an ET.

The predictability of a tropical-like cyclone downstream of the ET of Hurricane Helene (2006) is examined here in the European Centre for MediumRange Weather Forecasts (ECMWF) EPS. The smallscale cyclone took its origin from a low on the lee side of the Atlas Mountains and deepened on the Straight of Sicily (Moscatello et al. 2008b). It intensified quickly on the Ionian Sea and acquired a symmetric structure with a warm core and organized convection. Such a tropicallike cyclone is referred to as a Medicane (Mediterranean hurricane). This case of Medicane was the deepest one ever observed, with a recorded sea level pressure minimum of $986 \mathrm{hPa}$ at 0914 UTC 26 September 2006 (Moscatello et al. 2008b). Moscatello et al. (2008a) have attributed its quick intensification to its interaction with convection enhanced by the orography of Calabria, Italy. However, Chaboureau et al. (2012) have shown that the Medicane was formed only if convection was further enhanced by upward forcing induced from an upper-level jet. This upper-level jet was associated with an elongated upper-level trough, known as a potential vorticity $(\mathrm{PV})$ streamer.

ECMWF deterministic forecasts did not succeed in predicting the Medicane at lead times longer than $36 \mathrm{~h}$. This low predictability has been explained by the absence of a PV streamer in longer-range forecasts (Chaboureau et al. 2012). It was speculated that these features originated from a poor description of the ET of Helene. An impact of the ET on the synoptic conditions over the Mediterranean has been demonstrated by removing Helene from initial conditions (Pantillon et al. 2013). The dynamical linkage between an Atlantic ET and a Mediterranean cyclogenesis has been shown in a PV perspective (Grams et al. 2011). In the present study, such a dynamical linkage between Helene and the Medicane is established with the ECMWF EPS. It is shown that the forecast of the Medicane at midrange required a correct forecast of the ET of Helene. Targeted perturbations of the initial conditions in the vicinity of Helene and the upstream trough only led to the development of a Medicane at 84- and 108-h lead time.

The paper is organized as follows. Section 2 describes the clustering method used to categorize EPS members into different scenarios as well as the Méso-NH simulations used to test the sensitivity of forecasts to initial perturbations. Section 3 illustrates the performance of ECMWF deterministic and ensemble forecasts in predicting the track of Helene and the development of the Medicane. Section 4 presents two different scenarios in the ECMWF EPS for the ET of Helene to show the dynamical linkage between Helene and the Medicane. Section 5 identifies the origin of initial perturbations that improve the predictability of the Medicane. Section 6 concludes the paper. 


\section{Methods}

\section{a. Data}

This study is based on the operational forecasts of the ECMWF EPS from 20 to 25 September 2006. The forecasts are delivered twice a day at 0000 and 1200 UTC and contain 50 members in addition to a control forecast. For the sake of brevity, only forecasts initialized at 0000 UTC were used here. They are available on different interpolated vertical levels, including isobaric and 2-PVU surfaces [potential vorticity units (PVU); $1 \mathrm{PVU}=10^{-6} \mathrm{~K} \mathrm{~m}^{2} \mathrm{~kg}^{-1} \mathrm{~s}^{-1}$ ]. As of 2006 , ensemble forecasts were run for 10 days at T399 horizontal resolution (about $50 \mathrm{~km}$ ) with 62 vertical levels, while deterministic forecasts were run at T799 resolution (about $25 \mathrm{~km}$ ) with 91 vertical levels. Until now, the 50 EPS members start from perturbed initial conditions, computed from a random combination of singular vectors and from stochastic physics. Singular vectors are defined to maximize the growth of energy over $48 \mathrm{~h}$ in a tangent linearized model. Extratropical singular vectors are computed with dry physics and targeted poleward of $30^{\circ} \mathrm{N}$ or $30^{\circ} \mathrm{S}$. Tropical singular vectors are computed with moist physics and targeted on tropical cyclones, including those performing ET. See Leutbecher and Palmer (2008) for a detailed description of the ECMWF EPS.

\section{b. Ascending hierarchical classification}

To make use of an EPS during ET, Harr et al. (2008) have introduced a clustering method that reduces the large number of forecasts into a few scenarios. An alternative clustering method was applied here. Like in Harr et al. (2008), principal components, or empirical orthogonal functions, of the potential temperature $\theta$ on the dynamical tropopause were computed from the EPS members on a target region. Each member was then projected on the two first principal components in order to filter out the small-scale structures. In the present study, members were grouped iteratively into a predefined number of clusters with an ascending hierarchical classification. At each iteration, two groups of members were merged in such a way that the intragroup variance of filtered $\theta$ fields was minimized in each group. Compared to the fuzzy clustering analysis used by Harr et al. (2008), the ascending hierarchical classification does not depend on arbitrary initial cluster center, but it does not allow members to change cluster during the iteration process. This method has been extensively used in several studies for classifying cloud systems (e.g., Chaboureau and Claud 2006).

\section{c. Méso-NH numerical experiments}

The Méso-NH research model (Lafore et al. 1998), version 4.8 , was used to perform sensitivity experiments with the same configuration as in Pantillon et al. (2013). It was run at $24-\mathrm{km}$ horizontal resolution with 72 vertical levels, similar to the ECMWF deterministic forecast. Méso-NH was initialized from perturbed initial conditions, obtained through the addition of perturbations from selected members of the ECMWF EPS to the ECMWF control analysis. Méso-NH runs then used 6-hourly ECMWF operational analyses as lateral boundaries. Subgrid-scale transports were parameterized with mass-flux schemes for deep convection (Bechtold et al. 2001) as well as for shallow convection and thermals (Pergaud et al. 2009), and with a 1.5-order closure scheme for turbulence (Cuxart et al. 2000). Air-sea surface fluxes were parameterized according to Belamari (2005). The model further used a microphysical scheme for mixed-phase clouds (Pinty and Jabouille 1998) and a subgrid statistical cloud scheme (Chaboureau and Bechtold 2005).

\section{Forecasts of Helene and the Medicane in the ECMWF EPS}

The low predictability of Helene and the Medicane is first shown in the ECMWF deterministic forecast. A map of the potential temperature $\theta$ on the dynamical tropopause and of the mean sea level pressure (MSLP) depicts the synoptic situation over western Europe (Fig. 1). A low $\theta$ value corresponds to a trough (low tropopause) and a high $\theta$ value to a ridge (high tropopause). At the surface, the Medicane was marked in the ECMWF analysis by a small-scale low over the Adriatic Sea that rotated around a larger-scale low over the Tyrrhenian Sea (Fig. 1a). The presence of Helene was evident over the Atlantic, close to the western edge of the map. At the tropopause level, a PV streamer wrapped cyclonically around the large-scale low. The PV streamer was located downstream of a prominent ridge that was itself downstream of a trough connected with Helene.

Except at short range (not shown), operational deterministic forecasts delivered a poor prediction of Helene and the Medicane. In the latest deterministic forecast shown here, at 60 -h lead time, only a weak small-scale low was predicted around the larger-scale low (Fig. 1b). The upper-level trough was less elongated than in the analysis and a cutoff low replaced the PV streamer. Upstream, Helene was delayed with a southwestward shift. Both the small- and the larger-scale lows vanished from the Mediterranean in the longer-range 
(a) Analysis 1200 UTC 26 Sep

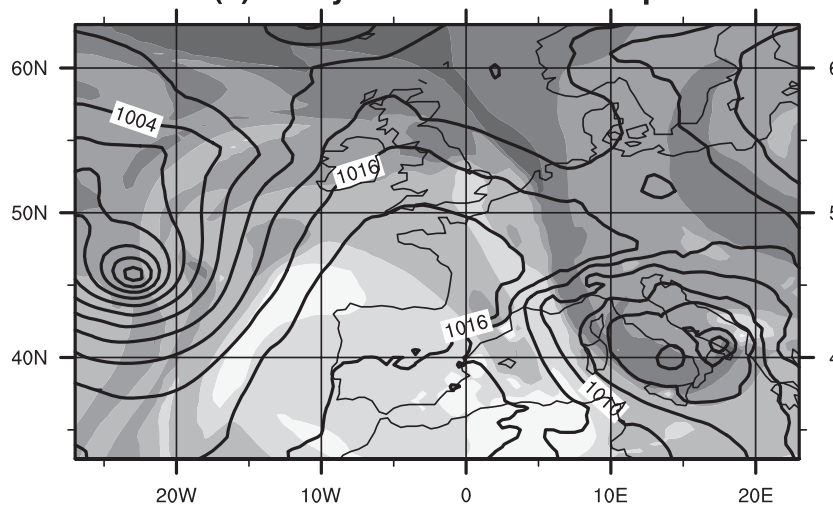

(c) Forecast init 0000 UTC $23 \operatorname{Sep}(\mathrm{t}+84)$

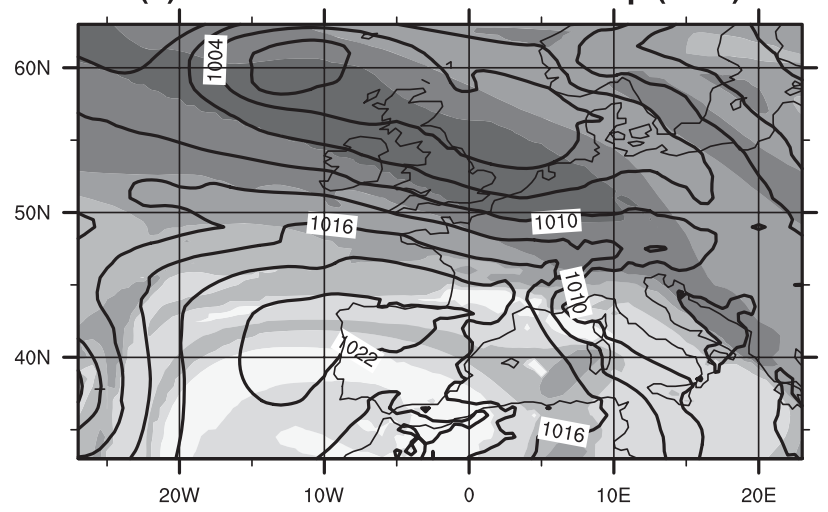

(e) Forecast init 0000 UTC 21 Sep (t+132)

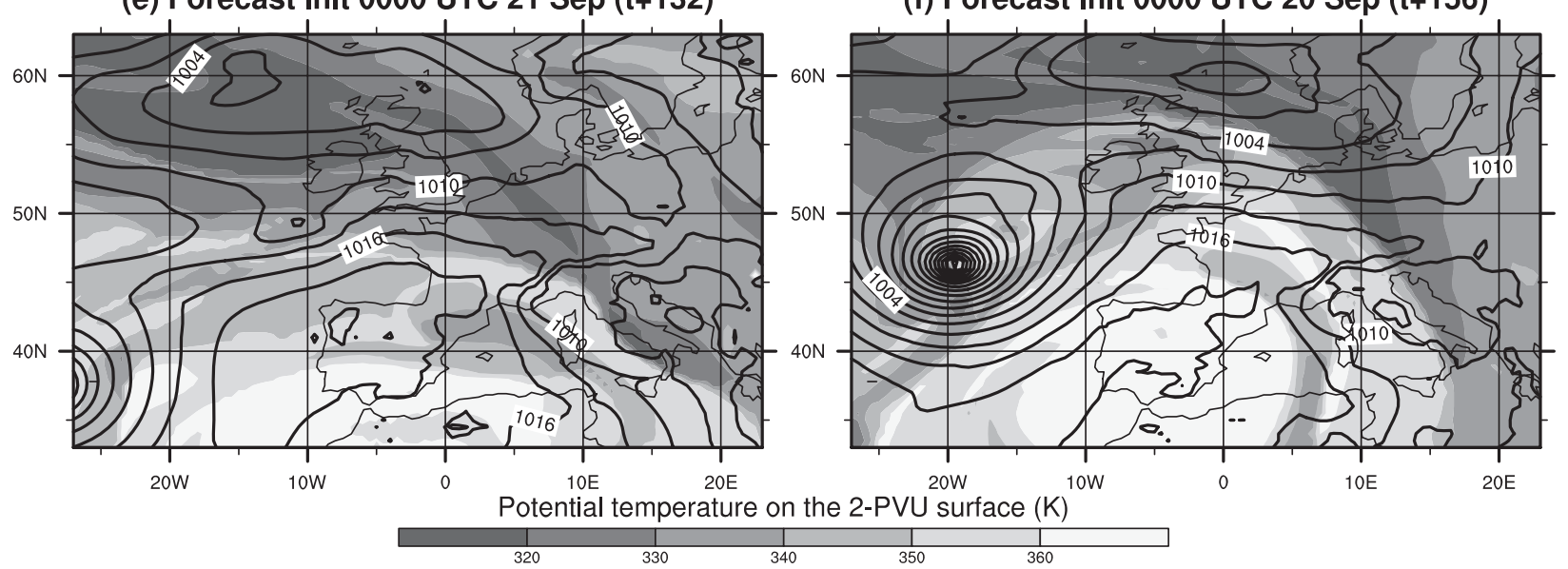

FIG. 1. Potential temperature on the dynamical tropopause defined by the surface at 2 PVU (shading) and MSLP (contour each $3 \mathrm{hPa}$ ) in the ECMWF analysis and deterministic forecasts initialized at 0000 UTC from 20 to 24 Sep 2006, all valid at 1200 UTC 26 Sep 2006.

forecasts at 84-, 108-, and 132-h lead time (Figs. 1c-e). The ridge upstream was replaced by a zonal trough with a corresponding broad low to the north of the British Isles. Helene was shifted farther southwestward, out of the map. At even a longer lead time surprisingly, the 156-h forecast predicted Helene quicker and with an MSLP minimum 20-hPa lower than in the analysis,

(b) Forecast init 0000 UTC $24 \operatorname{Sep}(t+60)$

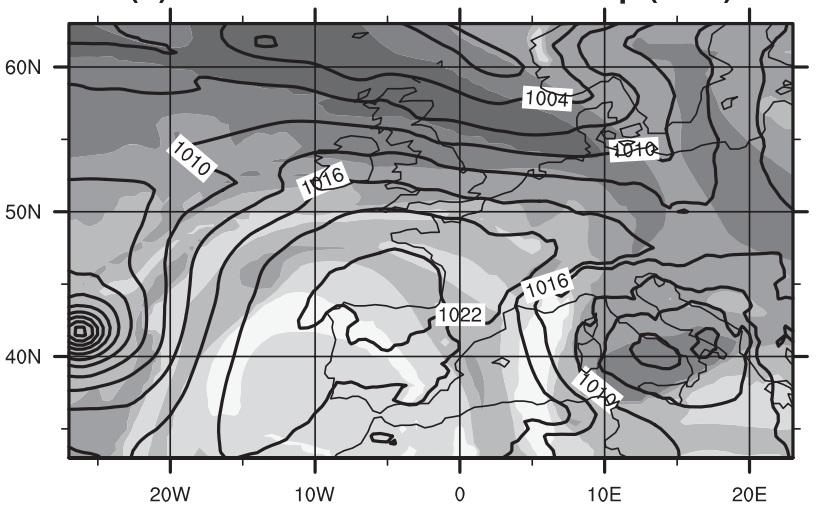

(d) Forecast init 0000 UTC $22 \operatorname{Sep}(t+108)$

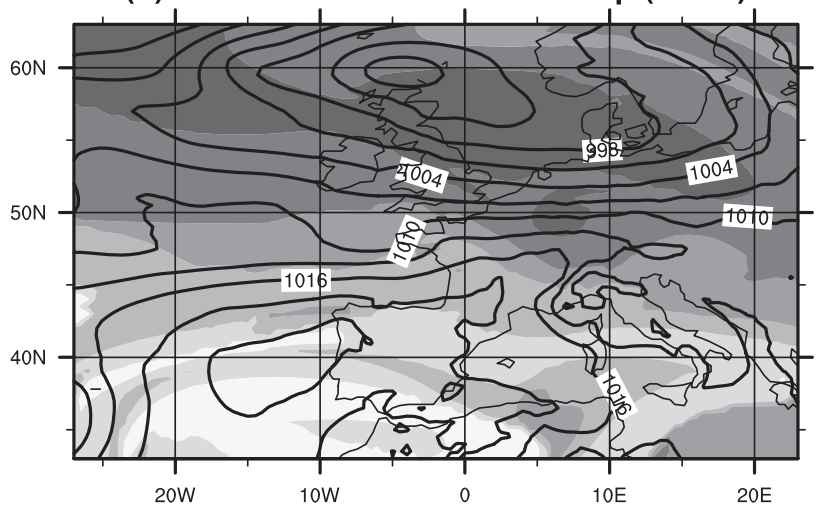

(f) Forecast init 0000 UTC 20 Sep $(t+156)$

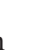


Chaboureau et al. (2012), who further showed the crucial presence of the PV streamer for the development of the Medicane. This relation is investigated here with EPS members from different initialization times. Although the consideration of different initialization times increases the number of members, the actual increase in statistical significance is unknown since consecutive ensemble runs are likely to be dependent on one another, at least to some degree, given current data assimilation systems. The low resolution of the operational ensemble forecast (about $50 \mathrm{~km}$ ) compared to the small diameter of the Medicane (about $60 \mathrm{~km}$; Moscatello et al. 2008b) requires a loose definition of the Medicane. Chaboureau et al. (2012) showed that short-term deterministic forecasts did not succeed in predicting the warm-core structure of the Medicane because of their too smooth horizontal resolution (about $25 \mathrm{~km}$ ). With the same horizontal resolution, the operational analysis showed a 994-hPa MSLP minimum of the small-scale low at 1200 UTC 26 September, much higher than the 986-hPa MSLP minimum recorded at 0914 UTC (Moscatello et al. 2008b).

In this study, the Medicane was defined as a smallscale Mediterranean low, rotating around a larger-scale low and reaching an MSLP minimum of $1000 \mathrm{hPa}$ or below between 0600 and 1800 UTC 26 September. This definition corresponds to a 6-hPa threshold of intensity error in a 12-h time window with respect to the analyzed value. No criterion was imposed on the thermal structure of the small-scale low. Though it might not develop the warm core of a tropical-like cyclone, the small-scale low is referred to as a Medicane for the sake of brevity. Additional numerical experiments were performed to verify the tropical characteristics of the Medicane in two successful ensemble forecasts (see section 5). With the above definition, the presence of a Medicane was searched for in the EPS with a tracking algorithm. Starting from the analyzed position of the Medicane at 0000 UTC 26 September, the MSLP minimum was tracked every $3 \mathrm{~h}$ within $2^{\circ}$ from its previous position (4 grid points, about $200 \mathrm{~km}$ ). The $2^{\circ}$ distance was set after the translation speed of the analyzed Medicane. A visual verification was required to exclude cases that converged toward the larger-scale low instead of following the small-scale low. Alternatively, the MSLP minimum was searched for without tracking algorithm but in a target area around its analyzed position. No additional Medicane was found and more cases had to be excluded, thus this alternative method was discarded.

With the tracking method and the above definition, the Medicane was searched for in all ensemble forecasts initialized at 0000 UTC from 20 to 25 September. Helene was searched for in the forecasts with the tracking

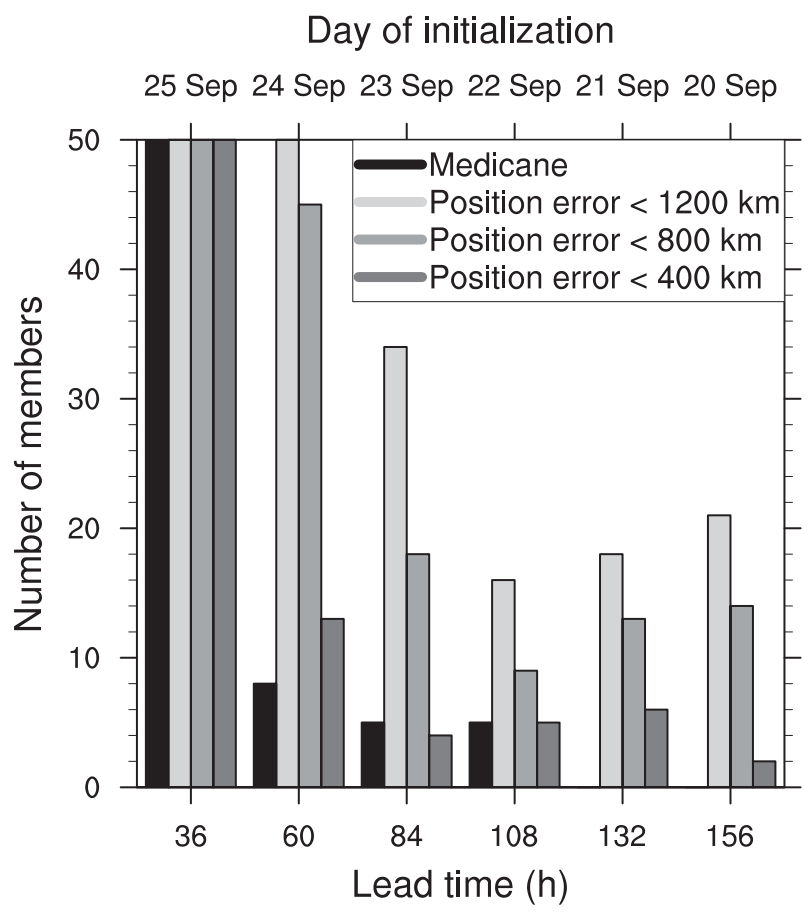

FIG. 2. Predictability of the Medicane and Helene at 1200 UTC 26 Sep 2006 in the ECMWF EPS from different lead times. Number of members predicting the Medicane and with a position error of Helene below 1200-, 800-, and 400-km thresholds.

algorithm, again every $3 \mathrm{~h}$ but within $3.5^{\circ}$ from its previous position. The error in the position of Helene was computed at 1200 UTC 26 September 2006. The first, second, and third quartiles of this error at all lead times were approximately 400, 800, and $1200 \mathrm{~km}$, respectively. All 50 forecasts at $36-\mathrm{h}$ lead time predicted both the development of the Medicane and a correct position of Helene within $400 \mathrm{~km}$ from its analyzed position (Fig. 2). The predictability of the Medicane dropped at longer range, with only 8,5 , and 5 out of 50 members predicting a Medicane at 60-, 84-, and 108-h lead time, respectively. No Medicane was found at 132- and 156-h lead time. The predictability of the position of Helene also diminished quickly. With a 400-km threshold of the position error, the predictability of the position of Helene dropped almost as quickly as the predictability of the Medicane (Fig. 2). With a more tolerant 800- or $1200-\mathrm{km}$ threshold, the predictability of the position of Helene decreased until the 108-h lead time, then slowly increased again.

These results from the ensemble forecasts confirm the low predictability at midrange of both the development of the Medicane and the position of Helene in the deterministic forecasts. The low number of members predicting the Medicane reveals that the forecast of such an intense small-scale cyclone is difficult. However, the 
recurrent and increasing occurrence of the Medicane from 108- to 60-h lead time might alert a forecaster of the possibility of such an event, even though it has low probability. This is a clear advantage of an ensemble forecast over a single deterministic forecast. The time period of decrease in the predictability of the position of Helene from 25 to 22 September corresponded to the ET of Helene, as defined from cyclone phase space diagrams (available at http://moe.met.fsu.edu/cyclonephase/ archive/2006/). Successive interactions between a Rossby wave train and Helene during its ET were responsible for the poor forecast skill (Pantillon et al. 2013). No further decrease in predictability occurred at higher lead time for forecasts initialized before the ET of Helene. Accordingly, Lang et al. (2012) found a peak of spread at 1200 UTC 21 September in the position and MSLP of Helene within an ensemble initialized with high-resolution singular vectors.

Conditional statistics could be applied to either confirm or dismiss a relation between the error position of Helene and the development of the Medicane (Fig. 2). At 60- and 84-h lead time, the proportion of members below any position threshold was higher in forecasts developing a Medicane than in other forecasts. It suggests a relation between both criteria. At 108-h lead time though, only one member successfully forecasted both the Medicane and the position of Helene within the $800-\mathrm{km}$ threshold. The position error of Helene lay above the $1200-\mathrm{km}$ threshold in all other four forecasts of the Medicane. This contradiction between different lead times cannot be elucidated with statistical arguments because the number of midrange forecasts developing a Medicane was too low. Instead of a statistical relation, a dynamical relation between Helene and the Medicane is investigated in the next section.

The impact of Helene on its environment was clear in the ensemble spread, which is a measure of uncertainty (Fig. 3). At all initialization times, the ensemble spread of the $500-\mathrm{hPa}$ geopotential height increased along the track of Helene. The ensemble spread in the track of Helene abruptly increased after $48 \mathrm{~h}$, which is the optimization time of singular vectors. In contrast, the spread of the geopotential height around Helene increased from 22 September and not after a particular lead time. That day marked the beginning of the ET of Helene. The ensemble spread of the geopotential height shows the usual decrease of predictability associated with ET. It propagated downstream and created a plume of uncertainty. The plume was located directly downstream of the track of Helene in early forecasts (Figs. 3a,b). It separated from the track of Helene in later forecasts (Figs. 3c-e) and its amplitude eventually vanished to the background spread (Fig. 3f). The direct connection between the plume of uncertainty and the track of Helene in early forecasts refers to the analyzed track. It is modulated by a systematic westward drift in most of ensemble and deterministic forecasts.

A relation between Helene and the Medicane might have existed if a perturbation that originated from Helene had propagated with the midlatitude flow until reaching the location of Medicane formation. It first required sufficient time for the perturbation to reach the location of the Medicane at its incipient stage. During an ET, the perturbation of the cyclone on the midlatitude flow can propagate downstream with the prograde group speed of a Rossby wave train (Riemer and Jones 2010). Its propagation is much quicker than the translation of the cyclone, which is steered with the retrograde phase speed of the Rossby wave train. The zonal group speed of the Rossby wave train that interacted with Helene during ET was estimated to be $35^{\circ}$ day $^{-1}$ (Pantillon et al. 2013). It is an upper limit for the propagation speed of a perturbation and therefore excludes a dynamical linkage between Helene and the Medicane in short-term forecasts starting at 0000 UTC 24 and 25 September (Figs. 3e,f). The dynamical linkage was possible at longer range only, in forecasts starting until 0000 UTC 23 September (Figs. 3a-d).

\section{Dynamical linkage between Helene and the Medicane}

Ensemble members were clustered after their description of the synoptic situation over western Europe, which suggested a dynamical linkage between Helene and the Medicane in deterministic forecasts (Fig. 1). All members from 0000 UTC 20 to 25 September were considered together in order to reveal systematic scenarios that did not depend on the initialization time. The clustering was targeted on the field of potential temperature $\theta$ on the dynamical tropopause at 1200 UTC 26 September.

Principal components of the $\theta$ field were computed in order to retain large-scale structures only. The first principal component was responsible for $26.1 \%$ of the variance among ensemble members (Fig. 4a). It showed a tripole pattern centered on the ridge downstream of Helene. The second principal component was responsible for $10.5 \%$ of the variance among ensemble members (Fig. 4b). It showed a dipole pattern, also centered on the ridge downstream of Helene. Such patterns and their related variance are typical of an ET event. They were described as an amplitude and a shift pattern, respectively (Anwender et al. 2008). Subsequent principal components, responsible for a lower variance among ensemble members, were not included. 

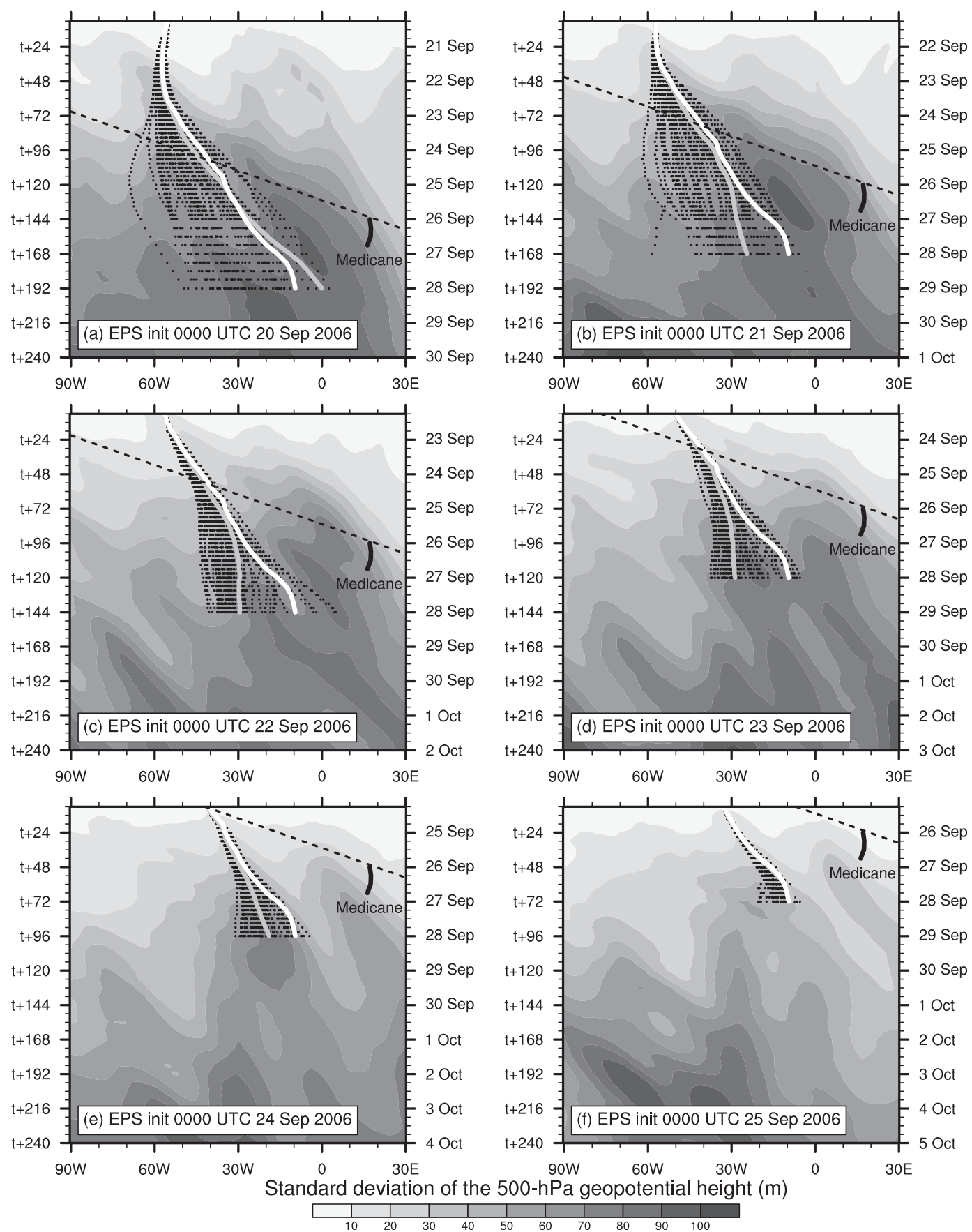

FIG. 3. Time-longitude (Hovmöller) plots of the ensemble spread in the 240-h ECMWF EPS initialized at 0000 UTC from 20 to 25 Sep 2006. The ensemble spread is defined as the standard deviation of the geopotential height at $500 \mathrm{hPa}$ averaged between $40^{\circ}$ and $60^{\circ} \mathrm{N}$ (shading, in m). Position of Helene in the ECMWF EPS (black dots), deterministic forecasts (gray curve), and analysis (white curve). The black curve around $15^{\circ} \mathrm{E}$ marks the position of the Medicane in the analysis. The dotted line represents a zonal speed of $35^{\circ} \mathrm{day}^{-1}$.

An ascending hierarchical classification was applied on all ensemble members, projected on the first two principal components. The number of clusters was set to 2. Cluster 1 contained 202 members whereas cluster 2 contained 98 members (Fig. 5). The partition between clusters was almost solely dependent on the projection on the first principal component, or amplitude pattern. An increase in the number of clusters split them 
(a) Principal component 1: $26.1 \%$ variance

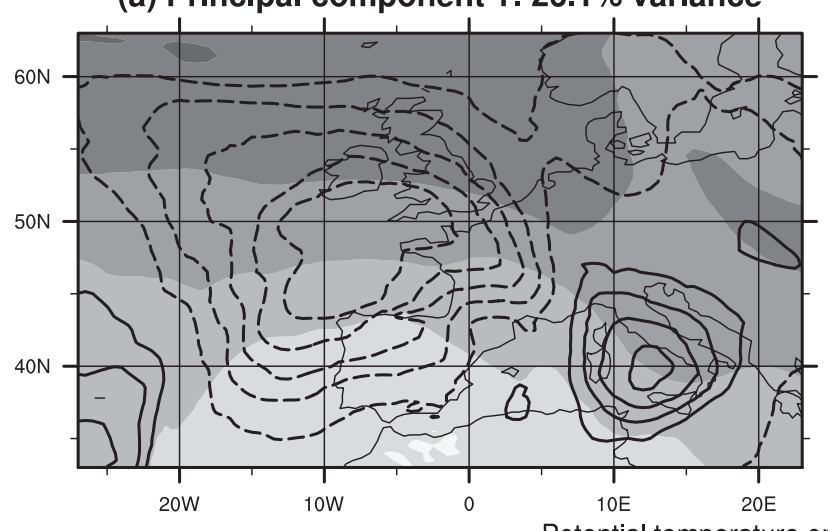

(b) Principal component 2: 10.5\% variance

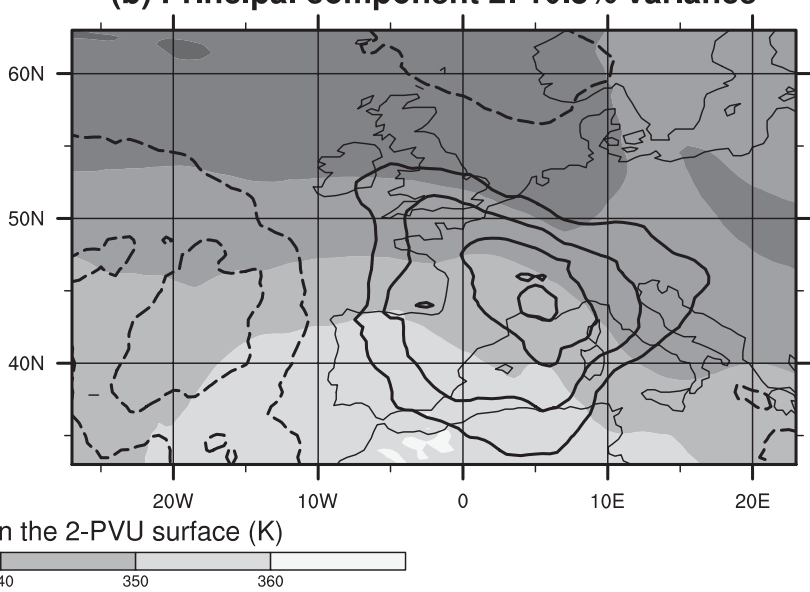

FIG. 4. Potential temperature on the dynamical tropopause at 1200 UTC 26 Sep 2006. Two first principal components (contours each 2 K, negative values dashed) and mean (shading in K) of all EPS members initialized at 0000 UTC from 20 to 25 Sep 2006.

according to their projection on the second principal component, or shift pattern. The partition into more than two clusters is not further discussed here because it did not increase the number of scenarios for the Medicane. The partition into two clusters was not very sensitive to the target area or verification time.

The number of ensemble members in each cluster depends on the lead time. All short-term ensemble forecasts, at 36- and 60-h lead time, were classified in cluster 1 and spread around the analysis in the space of the two first principal components (dense region of gray squares in Fig. 5). They predicted the correct synoptic situation over western Europe, as the corresponding deterministic forecasts did. A dynamical linkage between Helene and the Medicane in these forecasts was already dismissed, as discussed previously, because they were initialized too late for a perturbation that originated from Helene to propagate with the midlatitude flow until reaching the location of Medicane formation. In the following, only members from 84 - to 156 -h lead time were considered for further investigation, keeping 102 members in cluster 1 (i.e., discarding the other 100 members from 36- and 60-h lead times). The partition of members from 84- to 156-h lead time in the two clusters can be considered as equiprobable, with 102 and 98 members in clusters 1 and 2 , respectively. The number of ensemble members in cluster 1 decreased until 108-h lead time then increased again until 156-h lead time (inlet in Fig. 5). The same evolution was found in the predictability of the position of Helene (Fig. 2). Corresponding deterministic forecasts lay at the edge of the two clusters, except at 156-h lead time (not shown).

Average tropopause and surface fields clarify the partition in clusters. Cluster 1 was defined by a tropopause trough-ridge-trough pattern and a corresponding surface low-high-low pattern (Fig. 6a). The western low was located to the north of the analyzed position of Helene whereas the eastern low matched the large-scale low over Italy. Both were smoother than in any forecast because of the averaging process. Cluster 2 was defined by a broad tropopause trough and a corresponding broad surface low centered on the British Isles (Fig. 6b), which was more than $10-\mathrm{hPa}$ deeper than the low over Italy in cluster 1 . The two different patterns of synoptic situation over western Europe confirm the relation between the building of a ridge downstream of Helene and the presence of a large-scale low over Italy.

The classification of ensemble members in two clusters further allows a distinction between two scenarios in the evolution. Helene approached a Rossby wave train in the North Atlantic and began its ET on 22 September (Pantillon et al. 2013). Clusters distinguished only weakly from each other at that early time (Fig. 7a). The distinction between members at different lead times was stronger, albeit limited. During ET, the interaction of Helene with PV filaments from the Rossby wave train contributed to the building of the downstream ridge. The representation of this downstream ridge clearly differed between the clusters on 24 September (Fig. 7b). Whereas Helene was close to its analyzed position in cluster 1 , it suffered from a delay that was enhanced with the lead time in cluster 2 . The downstream ridge was also well built in cluster 1 whereas it was comparatively weaker in cluster 2 , which was again amplified with the lead time. This relation between Helene and the downstream ridge illustrates the importance of phasing during ET. A delay in the track of the cyclone or a weaker midlatitude flow can prevent the phasing of the 


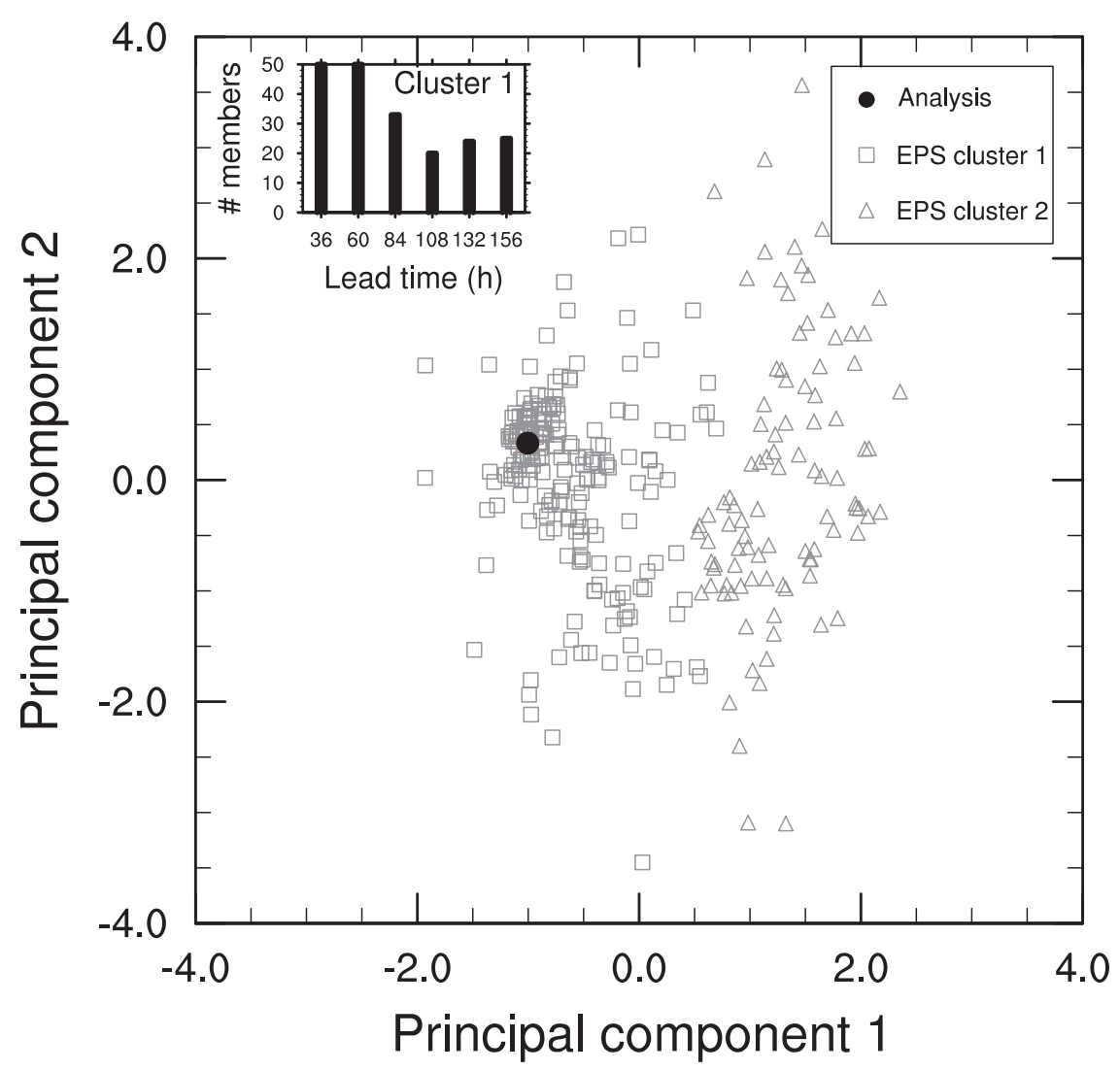

FIG. 5. Projection on the two first principal components at 1200 UTC 26 Sep 2006 of the ECMWF analysis (filled black circle) and ensemble forecasts (gray squares and triangles) initialized at 0000 UTC from 20 to 25 Sep 2006. Ensemble members are classified into two clusters. The inset shows the number of members belonging to the first cluster at each initialization time.

cyclone with an upstream trough and impact both the cyclone and the midlatitude circulation (Klein et al. 2002). If the environmental flow contains a bifurcation point, even a small difference in the cyclone-trough relative position can lead to a different cyclone reintensification and downstream evolution (Grams et al. 2013). Such a bifurcation point is hard to emphasize here, because the environmental flow evolved quickly and was impacted by the flow of Helene.

Differences in the downstream trough on 24 September were still more related to the lead time than to the cluster (Fig. 7b). During the development of the Medicane on 26 September, stronger differences had propagated from the ridge (Fig. 7c). The downstream trough elongated toward the Mediterranean in cluster 1 whereas it was absent from cluster 2 . Therefore, only cluster 1 contained essential synoptic conditions for the development of the Medicane (Chaboureau et al. 2012). Differences between clusters had also grown upstream of the Medicane. The delay in the track of Helene had increased and the downstream ridge was replaced by a trough. These differences were substantial but no longer relevant for the development of the Medicane. Overall, the classification of members by clusters was clearly more pertinent than their classification by lead time. It illustrates the existence of two different scenarios in ensemble forecasts during the ET of Helene that did not depend on the initialization time.

The partition in two clusters was strongly related to the evolution of Helene. Most ensemble members followed the analyzed track of Helene in cluster 1 (Fig. 8a). On average, about $80 \%$ of them lay below the $1200-\mathrm{km}$ threshold of position error at 1200 UTC 26 September, with the highest number of members below the threshold at $84 \mathrm{~h}$ and the lowest at 108-h lead time (inlet in Fig. 8a). Among outliers, many members diverged late from the analysis in showing a southward track of Helene on 25 September. This divergence occurred too late to impact on the Mediterranean on 26 September. In contrast, the track of Helene diverged earlier southward in most members of cluster 2 (Fig. 8b). Except at 84-h lead time, more than $90 \%$ of them lay above the $1200-\mathrm{km}$ 
(a) Cluster 1 init 20-23 Sep: 102 members

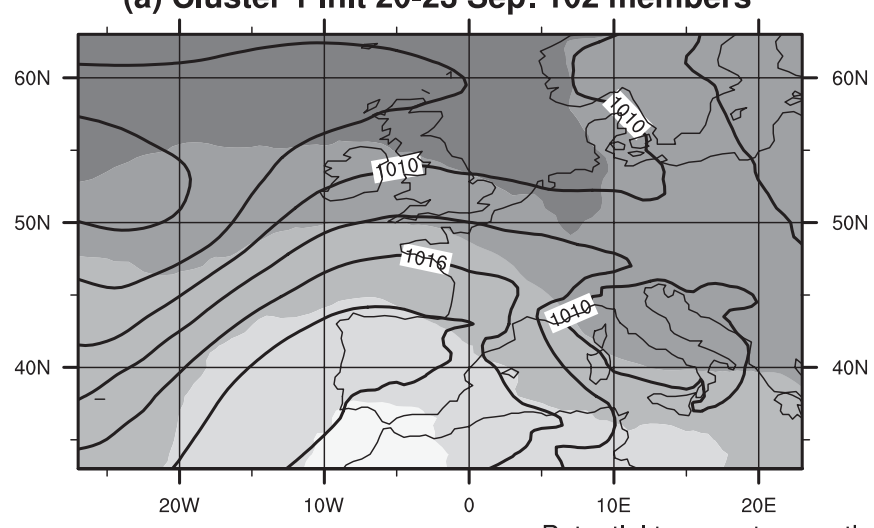

(b) Cluster 2 init 20-23 Sep: 98 members

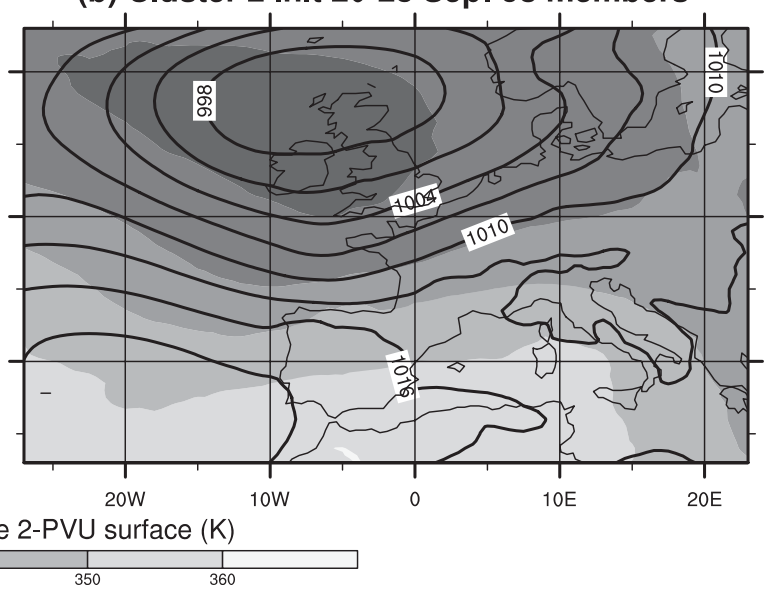

FIG. 6. Potential temperature on the dynamical tropopause (K, shading) and MSLP (contours each $3 \mathrm{hPa}$ ) at $1200 \mathrm{UTC} 26 \mathrm{Sep} 2006$, as in Fig. 1, but for the cluster means of all ensemble members initialized at 0000 UTC from 20 to 23 Sep 2006.

threshold of position error at 1200 UTC 26 September (inlet in Fig. 8b). The 1200-km threshold shown in Fig. 2 can be taken as an indicator of a southward divergence in the track of Helene. It approximately matches the partition between clusters but excludes members with a late southward divergence in cluster 1 .

The relation between Helene and the Medicane is clarified by the classification in two clusters. A Medicane developed in 9 out of 102 members in cluster 1 (Fig. 8a), while only 1 Medicane was found out of 98 members in cluster 2 (Fig. 8b). This comparison reveals that the probability for the development of the Medicane was much higher when the track of Helene was correctly forecast, at least until 24 September. Proper phasing of Helene with the Rossby wave train during ET was responsible for both the correct track of Helene and the building of a downstream ridge. It later brought favorable synoptic conditions over Europe for the development of the Medicane. The relation between the position of Helene, the building of the ridge, the elongation of the trough and surface cyclogenesis, which was apparent in deterministic forecasts, is confirmed from the cluster analysis in ensemble forecasts.

As cluster 1 contained all but one successful member, the proper phasing of Helene with the Rossby wave train was a quasi-necessary condition for the development of the Medicane. It was not a sufficient condition however, as most of the members in cluster 1 did not develop the Medicane. A deeper investigation did not show any relevant differences in the track of Helene between successful and unsuccessful forecasts from cluster 1 . Among the five members that developed the Medicane at 108-h lead time, only one forecasted the position of Helene within the $800-\mathrm{km}$ threshold. The other four members forecasted Helene with a position error above the $1200-\mathrm{km}$ threshold. Three of them belonged to cluster 1, with correct synoptic conditions over the Mediterranean but a late, wrong southward track of Helene. The last among the other four members at 108-h lead time was the only member from all initialization times that belonged to cluster 2 and still predicted the Medicane. In this case, a cutoff low formed early over the Mediterranean and allowed the development of the Medicane, though wrong synoptic conditions over western Europe. At 84-h lead time, all five members that developed the Medicane belonged to cluster 1. Among them, four forecasted the position of Helene within the 800-km threshold, from which one forecasted the position of Helene within the $400-\mathrm{km}$ threshold. The last among the five members at 84 -h lead time forecasted Helene with a position error above the $1200-\mathrm{km}$ threshold. It also showed correct synoptic conditions over the Mediterranean though a late, wrong southward track of Helene. For members of cluster 1, this investigation confirms that the $1200-\mathrm{km}$ threshold is an indicator of a southward divergence in the track of Helene, but shows that it is not a constraint on the development of the Medicane.

\section{Origin of uncertainty in the prediction of the Medicane}

By construction, perturbations in the initial conditions are applied globally in the ECMWF EPS. As they are built to optimize the growth of total energy within $48 \mathrm{~h}$, some of them strongly impact the forecasts whereas others vanish at longer range. A member-to-member comparison of initial conditions does not tell which 

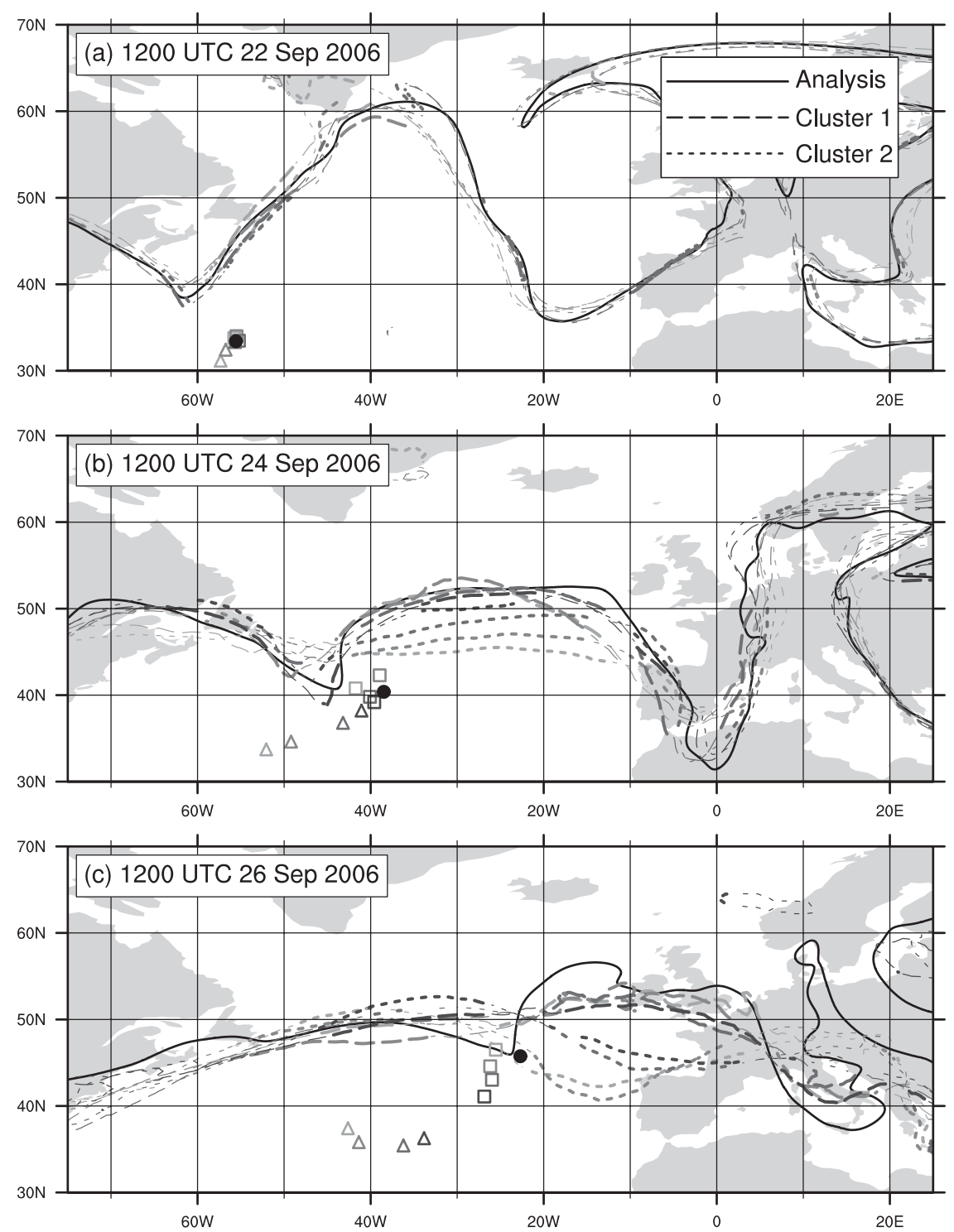

FIG. 7. 335-K contour of the potential temperature on the dynamical tropopause in the ECMWF analysis and cluster means of ensemble members initialized at 0000 UTC from 20 to 23 Sep 2006. Symbols show the position of Helene in the analysis (circle), cluster-1 means (squares), and cluster-2 means (triangles). The light-to-dark shading of cluster contours and symbols indicate their initialization time from 20 to $23 \mathrm{Sep}$. Contours are in bold where cluster means are statistically different with a $95 \%$ confidence.

perturbations are important at midrange. Only a clusterto-cluster comparison reveals areas of higher sensitivity. At each initialization time from 20 to 23 September, differences in MSLP between cluster 1 and cluster 2 were emphasized where they are statistically significant (Fig. 9). In the earliest forecast (Fig. 9a), a positive anomaly of MSLP to the right of the track of Helene was significant for the forecasts to be classified in cluster 1 . This anticyclonic anomaly accelerated Helene northward and improved its phasing with the Rossby wave train. In later forecasts (Figs. 9b-d), a negative anomaly of MSLP to the left of the track of Helene was crucial for the forecasts to be classified in cluster 1 . This cyclonic anomaly enhanced the northeastward steering of Helene from the upstream trough, and again improved its phasing with the Rossby wave train.

Through a classification of ensemble members in four clusters, Harr et al. (2008) examined the perturbations to initial conditions leading to different scenarios during the extratropical transition of Typhoon Nabi (2005). 

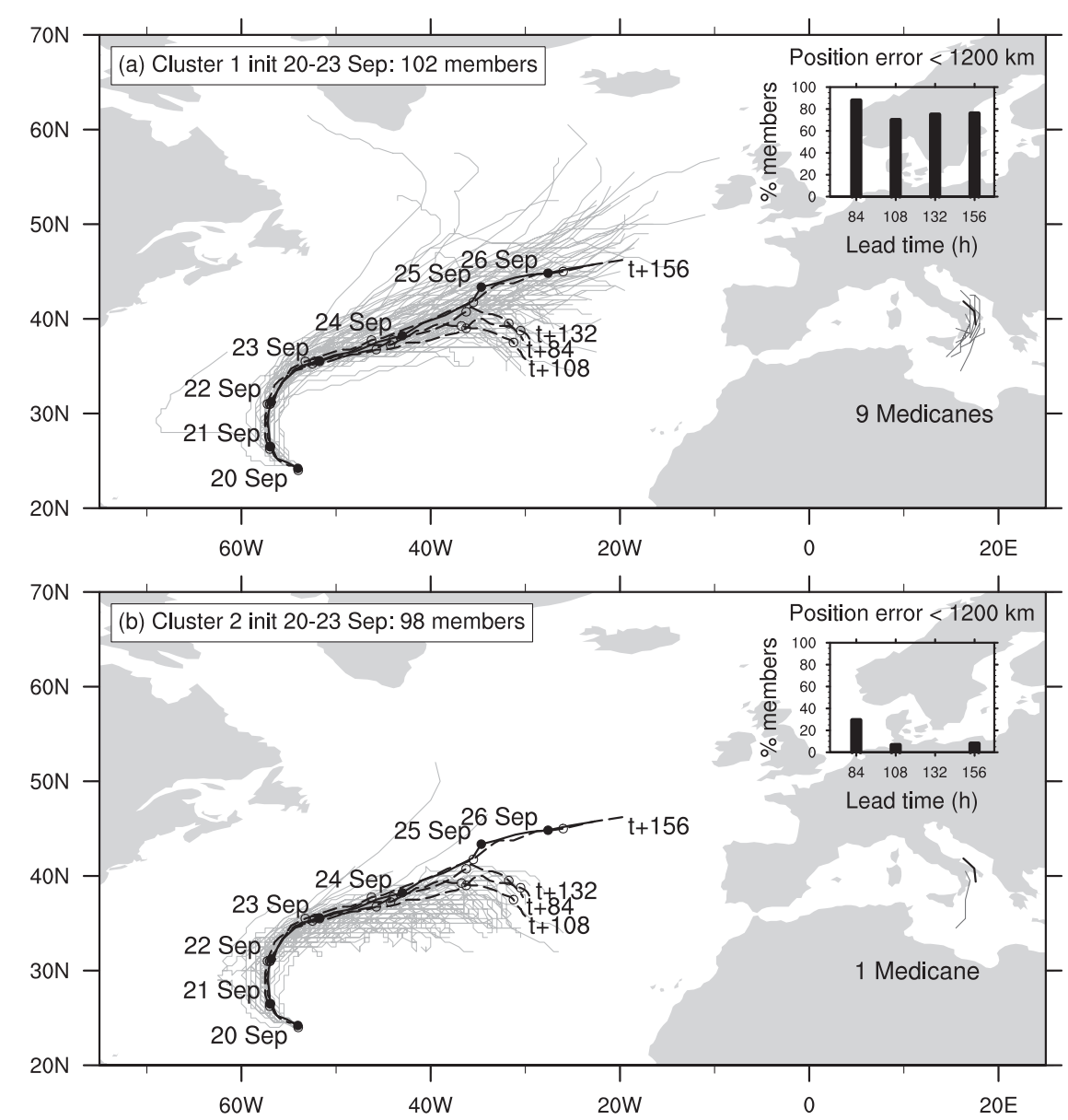

FIG. 8. Tracks of Helene until 1200 UTC 26 Sep 2006 and tracks of the Medicane on 26 Sep 2006 in each cluster. Tracks in the ECMWF analysis (solid black line), deterministic forecasts (dashed black lines), and ensemble forecasts (gray lines) from 20 to 23 Sep 2006. Dots indicate the position of Helene at 0000 UTC. The insets show the percentage of members in each cluster with a position error of Helene smaller than $1200 \mathrm{~km}$ at 1200 UTC 26 Sep 2006.

They found that the largest differences between clusters were associated with different representations and locations of Nabi. When a negative anomaly of MSLP was located ahead of Nabi at initialization time, the resulting positions of both Nabi and the downstream ridge were shifted to the east. Like Helene, the phasing of Nabi with the upstream trough was improved when Nabi was located closer to the trough at initialization time. This illustrates that initial perturbations located around both the tropical cyclone and the upstream trough can improve their phasing. In the case of Helene however, differences in the initial conditions between clusters were also statistically significant in other areas, like the Canadian Maritimes (Fig. 9a), Greenland (Fig. 9b), western Europe (Fig. 9c), or Scandinavia (Fig. 9d). These differences might have impacted the synoptic situation over western Europe at 1200 UTC 26 September, too.
To find the areas of sensitivity for the synoptic situation over western Europe, initial perturbations were further investigated with Méso-NH experiments (see section 2). At 0000 UTC on both 22 and 23 September, the member of the ECMWF EPS that forecasted the Medicane and showed the lowest position error of Helene was chosen for sensitivity experiments. At each initialization time, three experiments were performed until 0000 UTC 27 September. A large simulation domain encompassed Helene, the western Mediterranean, and three troughs from the Rossby wave train that played an important role during the ET of Helene (Fig. 10). At each initialization time, a control experiment (hereafter CTRL22 and CTRL23, respectively) used initial conditions from the control forecast of the ECMWF EPS. Perturbed experiments used initial conditions from the successful member of the ECMWF EPS mentioned above. These perturbations were located 
(a) EPS init 0000 UTC 20 Sep

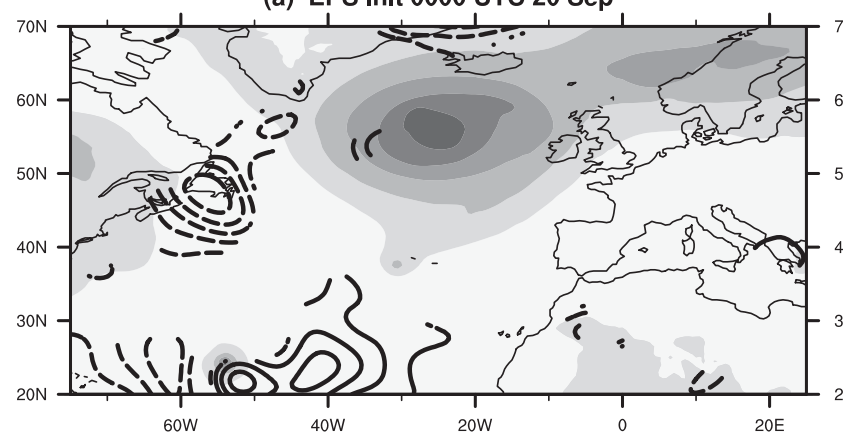

(c) EPS init 0000 UTC 22 Sep

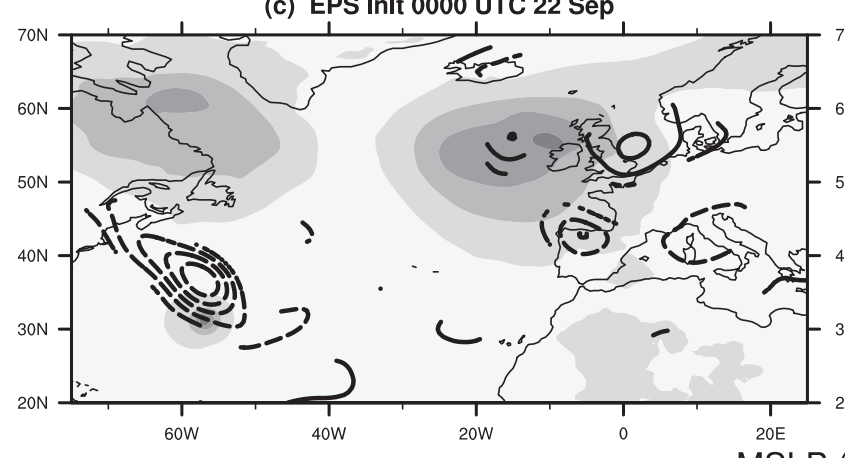

MSLP $(\mathrm{hPa})$

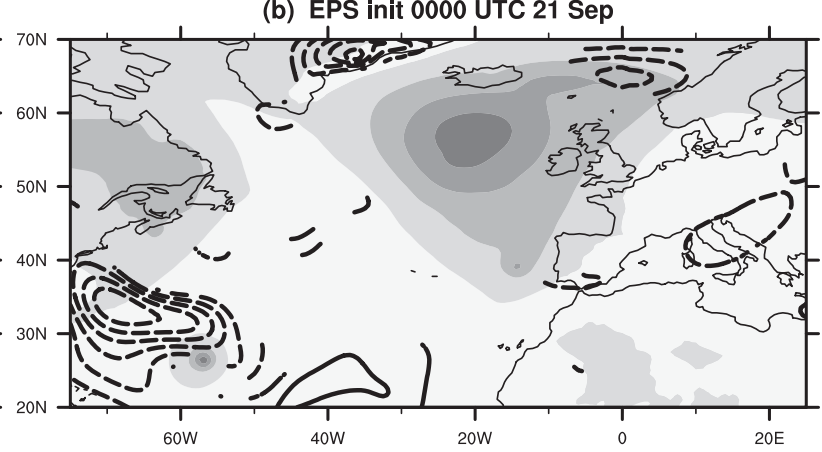

(d) EPS init 0000 UTC 23 Sep

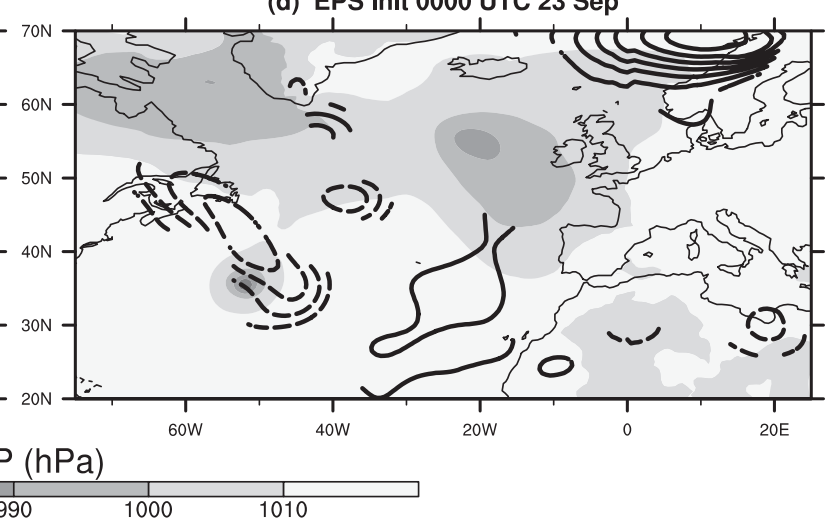

FIG. 9. MSLP from the ECMWF analysis (hPa, shading) and difference in the mean MSLP between clusters 1 and 2 (contours each $0.1 \mathrm{hPa}$, negative values dashed) at four initialization times. Contours are shown only where cluster means are statistically different with a $95 \%$ confidence.

in the vicinity of Helene and along the gradient of upperlevel vorticity, where energy concentrates as jet streaks (contours in Fig. 10). At each initialization time, a targeted experiment (hereafter TARG22 and TARG23, respectively) used perturbed initial conditions in an area including Helene and the Atlantic trough, and nonperturbed initial conditions elsewhere (dashed rectangles in Fig. 10). Compared to the other members that developed the Medicane, the vertically integrated total energy of initial perturbations in this area was rather low in TARG22 whereas it was closer to the average in TARG23. Targeted perturbations in the wind field had a maximal amplitude of about $2 \mathrm{~m} \mathrm{~s}^{-1}$ and were located along jet streaks. Targeted perturbations in the temperature field had a maximal amplitude of about $1 \mathrm{~K}$ and did not organize as a coherent structure. At each initialization time, a complementary experiment (hereafter COMP22 and COMP23, respectively) used nonperturbed initial conditions in the area including Helene and the Atlantic trough, and perturbed initial conditions elsewhere.

Both targeted Méso-NH experiments TARG22 and TARG23 successfully forecasted a small-scale low over the Adriatic Sea at 1200 UTC 26 September (Figs. 11b,e).
TARG22 reached an MSLP minimum of $993 \mathrm{hPa}$ at 1200 UTC and a minimum of $992 \mathrm{hPa}$ at $1500 \mathrm{UTC}$. These values were very close to the MSLP minimum of $994 \mathrm{hPa}$ at 1200 UTC in the ECMWF analysis with a similar horizontal resolution (about $25 \mathrm{~km}$ ). The corresponding successful perturbed forecast from the EPS reached a higher MSLP minimum of $1000 \mathrm{hPa}$, which is explained by its lower horizontal resolution (about $50 \mathrm{~km}$ ). In TARG23, the small-scale low reached a deeper MSLP minimum of $989 \mathrm{hPa}$ at 1200 UTC, closer to the recorded value of $986 \mathrm{hPa}$ at 0914 UTC. The corresponding successful perturbed forecast from the EPS again reached a higher MSLP minimum of $995 \mathrm{hPa}$. The small-scale low was rotating around a larger-scale low in both TARG22 and TARG23 (Figs. $11 \mathrm{~b}, \mathrm{e})$. In conformance with its actual evolution, it developed from the lee side of the Atlas Mountains (Moscatello et al. 2008b) and deepened during the crossing of an upper-level jet (Chaboureau et al. 2012). The small-scale low was shifted about 400 and $200 \mathrm{~km}$ to the northwest in TARG22 and TARG23, respectively, compared to the observation and analysis (Fig. 11a). This shift resulted from a shift in the location of the upper-level jet, which caused a shift in the location of 

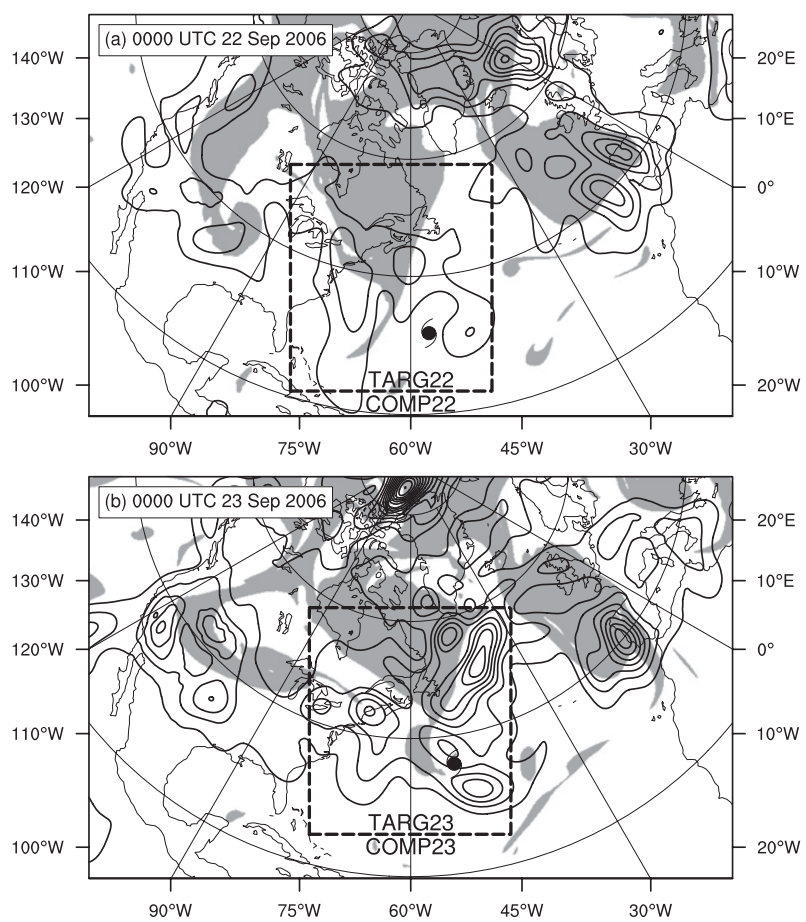

FIG. 10. Initial fields of the Méso-NH simulations at 0000 UTC (a) 22 and (b) 23 Sep 2006. Position of Helene (cyclone symbol) and 250-hPa potential vorticity (shaded above 2 PVU) in the ECMWF analysis and vertically integrated total energy of initial perturbations in the selected members of the ECMWF EPS (contours each $5 \times$ $10^{4} \mathrm{~J} \mathrm{~Pa} \mathrm{~kg}^{-1}$ ). The dashed rectangles in (a) and (b) separate the area of initial perturbations in Méso-NH targeted experiments TARG22 and TARG23 from complementary experiments COMP22 and COMP23, respectively.

the larger-scale low and the associated cloud pattern as well.

At $t+108$, neither the control CTRL22 (Fig. 11c) nor the complementary experiment COMP22 (not shown) forecasted a small-scale low. In these experiments, the upper-level jet was shifted northward and a surface low was lacking. Both ingredients for the development of a small-scale low were missing. The similarity of COMP22 and CTRL22 shows that initial perturbations applied at 0000 UTC 22 September around the Mediterranean trough had a minor impact on its midrange evolution $108 \mathrm{~h}$ later. At $t+84$ in contrast, both the control CTRL23 and the complementary experiment COMP23 forecasted a small-scale low (Figs. 11d,f). In CTRL23, the low had a too zonal track and the upperlevel jet was rather straight. As a consequence, the low was shifted about $400 \mathrm{~km}$ to the southeast and deepened less than in TARG23 during its delayed crossing of the upper-level jet. In COMP23, the low had an even more zonal track and did not cross the upper-level jet that was even straighter. In this case, initial perturbations applied at 0000 UTC 23 September around the Mediterranean trough had a negative impact on its midrange evolution $84 \mathrm{~h}$ later. The successful forecasts in TARG22 and TARG23 show that initial perturbations around Helene and the Atlantic trough had a crucial impact on the midrange evolution of the Mediterranean trough. Their impact was bigger at 0000 UTC 22 September, when the control experiment CTRL22 missed the development of the small-scale low. The impact of initial perturbations was smaller at 0000 UTC 23 September, when both the targeted TARG23 and control experiment CTRL23 forecasted the small-scale low, thanks to the shorter forecast range.

The small-scale low that developed in TARG22 and TARG23 was classified as a Medicane accordingly to the definition given in section 3 applied to the ECMWF EPS. A detailed examination of its structure is allowed from output fields of the Méso-NH experiments. The small-scale surface low developed downstream of an upper-level cutoff low from the elongated upper-level trough (Figs. 12a,b). The cutoff low was more isolated in TARG23 than in TARG22, because of its earlier separation from the trough. In TARG22 and TARG23, the vertical structure of the surface low reveals a tilted PV tower extended up to $500 \mathrm{hPa}$ (Figs. 12c,d). The low tropopause upstream of the tilted PV tower suggests a baroclinic interaction for the intensification of the small-scale low. The superposition of positive PV anomalies in TARG23 shows a mature system (Fig. 12d), which explains the deeper surface low than in TARG22 (Fig. 12c). In TARG22 and TARG23, a warm anomaly along the PV tower up to $500 \mathrm{hPa}$ supports the tropical-like structure of the low. It is in accordance with the classification of the low as a Medicane. A realistic forecast of such a mesoscale storm was therefore possible at $84-$ and 108 -h lead time.

The evolution of the different sensitivity experiments emphasizes the importance of the initial conditions (Fig. 13). Targeted experiment TARG22 diverged quickly with an acceleration of Helene in accordance with an early breaking of the upstream trough. This divergence increased until the end of ET at 0000 UTC 25 September, when the downstream ridge had much greater meridional extent in TARG22 than in the analysis, CTRL22, and COMP22 (Fig. 13a). As a consequence, the downstream trough was prevented to merge with the upstream trough and elongated into a PV streamer toward the Mediterranean in TARG22, unlike CTRL22 and COMP22. It eventually broke as a cutoff low that enabled the development of the Medicane (Figs. 12a,c). In contrast with TARG22, TARG23 remained close to the analysis. At the end of ET at 0000 UTC 25 September, the downstream ridge had a correct 

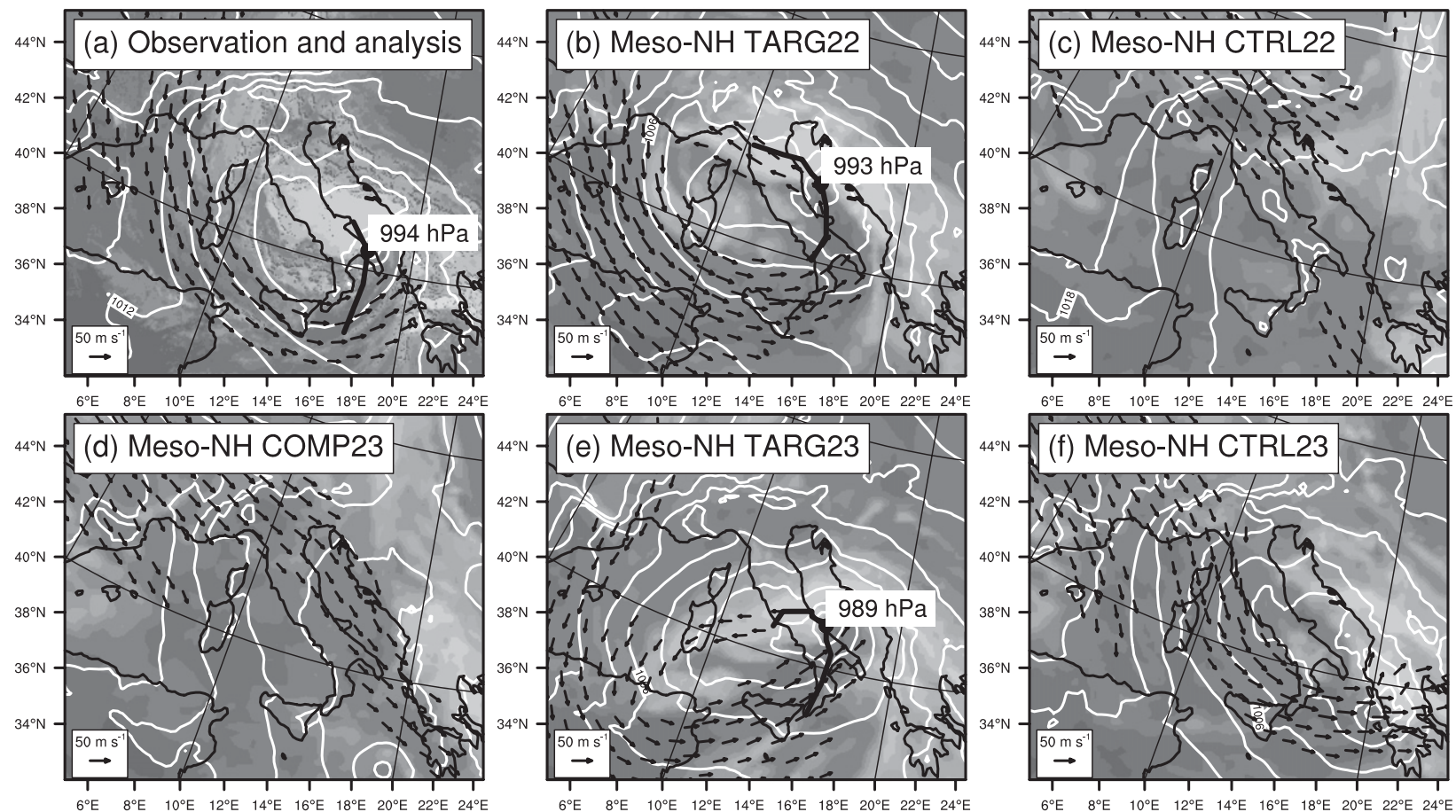

IR brightness temperature $(\mathrm{K})$

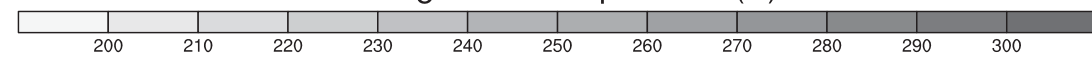

FIG. 11. Infrared (IR) brightness temperature (shading, in K), 250-hPa wind (arrows above $30 \mathrm{~m} \mathrm{~s}^{-1}$ ), and MSLP (contours each $3 \mathrm{hPa}$ ) from (a) satellite observation from the globally merged IR brightness temperature data and ECMWF analysis, and (b)-(f) Méso-NH experiments computed with the Radiative Transfer for the TIROS Operational Vertical sounder (RTTOV) algorithm (Saunders et al. 2005), all at 1200 UTC 26 Sep $2006(t+108)$. The black curve in (a),(b), and (e) shows the track of the Medicane.

meridional extent in TARG23, unlike CTRL23 and COMP23 (Fig. 13b). The downstream trough also elongated until it broke as a cutoff low and enabled the development of the Medicane in TARG23 (Figs. 12b,d), while its breaking was delayed in CTRL23 and absent from COMP23.

Through their successful development of the Medicane, targeted experiments TARG22 and TARG23 reveal the sensitivity in the midrange forecast to the initial conditions of Helene and the upstream trough. This sensitivity supports the need for targeted observations on a cyclone and the upstream trough during an ET event, as suggested by Torn (2010). Such adaptive observations would compensate for the lack of wind and water vapor measurements from either in situ or remote instruments on the open ocean. They could improve the forecast downstream of an ET event, in particular of high-impact weather. Though they did not impact the downstream trough, initial perturbations in COMP22 improved the track of Helene from a late acceleration toward its position in TARG22 (not shown). These differences between COMP22 and CTRL22 propagated from a trough over North America, as in previous sensitivity experiments (Pantillon et al. 2013). They show the sensitivity to initial conditions far upstream of an ET event in the forecast of the track of the cyclone and support the importance of observations in these regions, too (Reynolds et al. 2009; Torn and Hakim 2009).

Beyond the successful development of the Medicane, initial perturbations in TARG22 did not only improve the forecast but had a complex impact. The evolution of Helene and the downstream ridge until the end of ET at 0000 UTC 25 September were closer to the analysis in the other two experiments CTRL22 and COMP22 (Fig. 13a). However, the downstream trough broke anticyclonically in CTRL22 and COMP22, with an eastward shift compared to the analysis. This shift increased until 26 September and did not allow the development of the Medicane. As initial perturbations in TARG22 brought an early divergence of Helene and the Rossby wave train compared to the analysis, they had a negative impact on the forecast over the North Atlantic. But as they allowed the development of the Medicane, they had a positive impact on the forecast over the Mediterranean. This complex impact suggests that initial perturbations in 

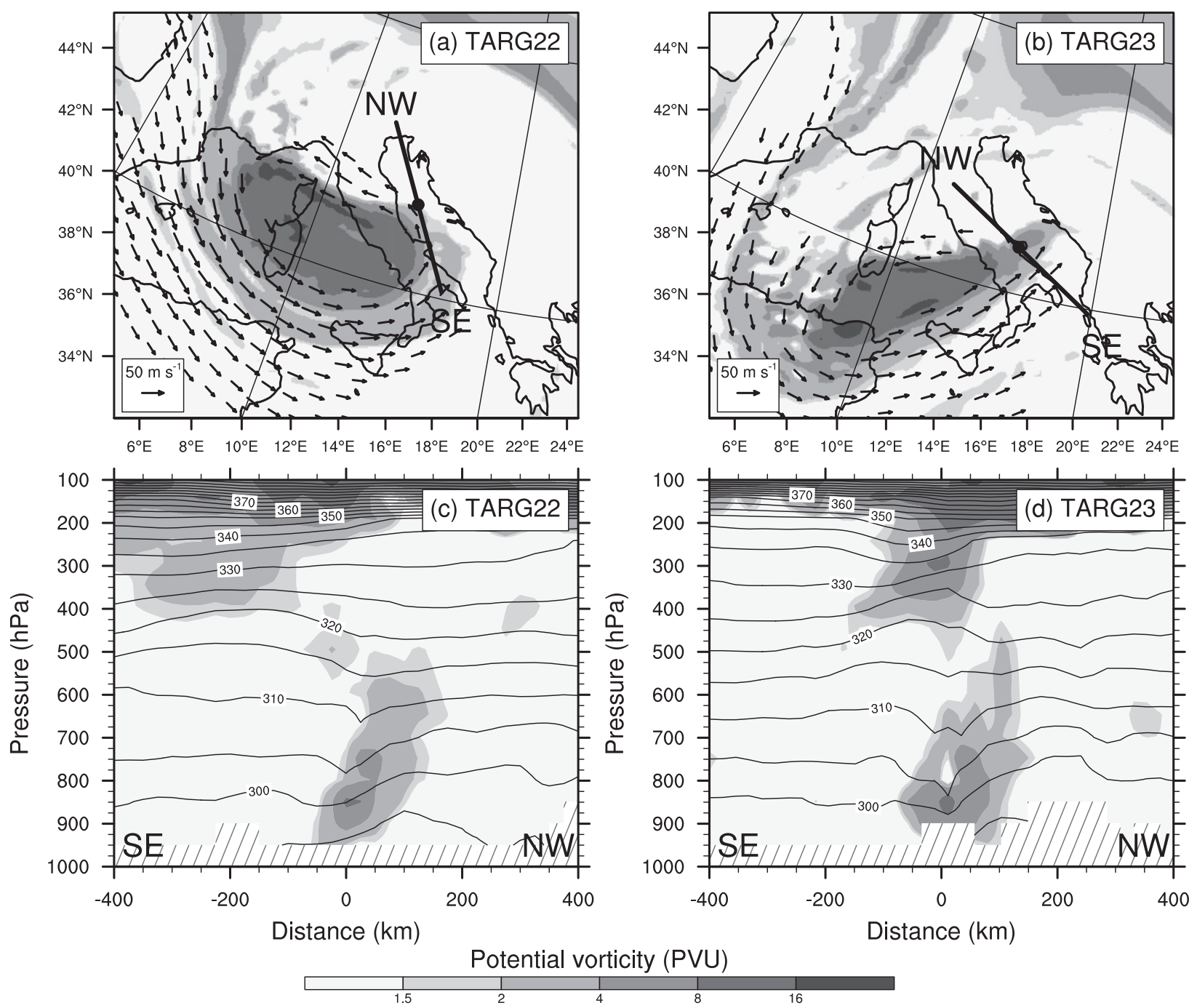

FIG. 12. Potential vorticity (shading, in PVU) in Méso-NH (a),(c) TARG22 and (b),(d) TARG23 experiments at 1200 UTC 26 Sep 2006 , in (a),(b) 250-hPa horizontal cross sections (with wind arrows above $30 \mathrm{~m} \mathrm{~s}^{-1}$ ) and (c),(d) southeast-northwest vertical cross sections (with contours of potential temperature each $5 \mathrm{~K}$ ). The thick lines in the horizontal cross sections in (a) and (b) show the location of the vertical cross sections in (c) and (d), respectively.

TARG22 were exaggerated in the building of the ridge but compensated for model errors in the dynamics of the trough downstream. An inadequate equatorward extension of PV streamers is a known error in models of numerical weather prediction over the Mediterranean (Dirren et al. 2003).

The propagation of differences between targeted and control experiments is summarized in a Hovmöller plot (Fig. 14). In TARG22 and TARG23, the southerly upperlevel jet downstream of Helene (positive values near $60^{\circ} \mathrm{W}$ on 23 September) was quicker than in CTRL22 and CTRL23, respectively. This acceleration propagated eastward and was found on 24 September in the northerly (negative values between $30^{\circ}$ and $15^{\circ} \mathrm{W}$ ) and southerly (positive values between $15^{\circ} \mathrm{W}$ and $0^{\circ}$ ) upper-level jets farther downstream. These northerly and southerly jets were located on the western and eastern sides of the upper-level trough over the Mediterranean, respectively (Figs. 12a,b). In both TARG22 and TARG23, the southerly upper-level jet intensified until 25 September, then allowed the development and deepening of the Medicane on 26 September (Fig. 14). The early acceleration of the upper-level jet over the Atlantic in TARG22 and TARG23 was therefore responsible for the later acceleration of the upper-level jet over the Mediterranean. It quickly propagated downstream with a zonal speed of about $35^{\circ}$ day $^{-1}$ (Fig. 14), which is the zonal group speed of the Rossby wave train that interacted with Helene during its ET. As in the cluster-1 mean (Fig. 7), initial perturbations in TARG22 

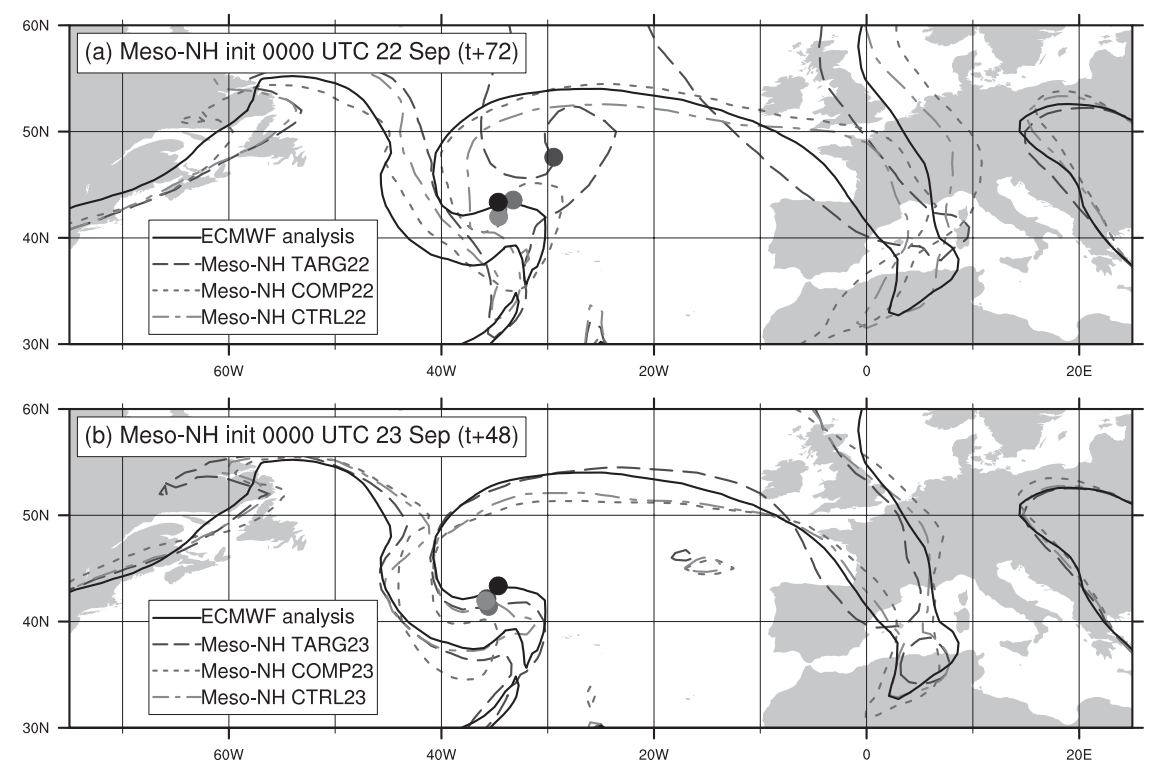

FIG. 13. Spaghetti plots at 0000 UTC 25 Sep 2006. Smoothed PV contour at $250 \mathrm{hPa}$ (contours at $2 \mathrm{PVU}$ ) and position of Helene (filled circles) in the ECMWF analysis (black) and Méso-NH targeted experiments TARG22 and TARG23 (dark gray), complementary experiments COMP22 and COMP23 (middle gray), and control experiments CTRL22 and CTRL23 (light gray).

and TARG23 amplified the Rossby wave train through its enhanced phasing with Helene.

\section{Conclusions}

A rare Mediterranean tropical-like cyclone, or Medicane, developed on 26 September 2006 (Moscatello et al. 2008b) downstream of the ET of Helene. Its predictability was investigated in the ECMWF EPS. A high spread characterized the ET of Helene from 22 to 25 September and propagated downstream. The Medicane was present in the ECMWF deterministic forecast up to 36-h lead time only and its predictability in the EPS dropped from all 50 to a few members at higher lead

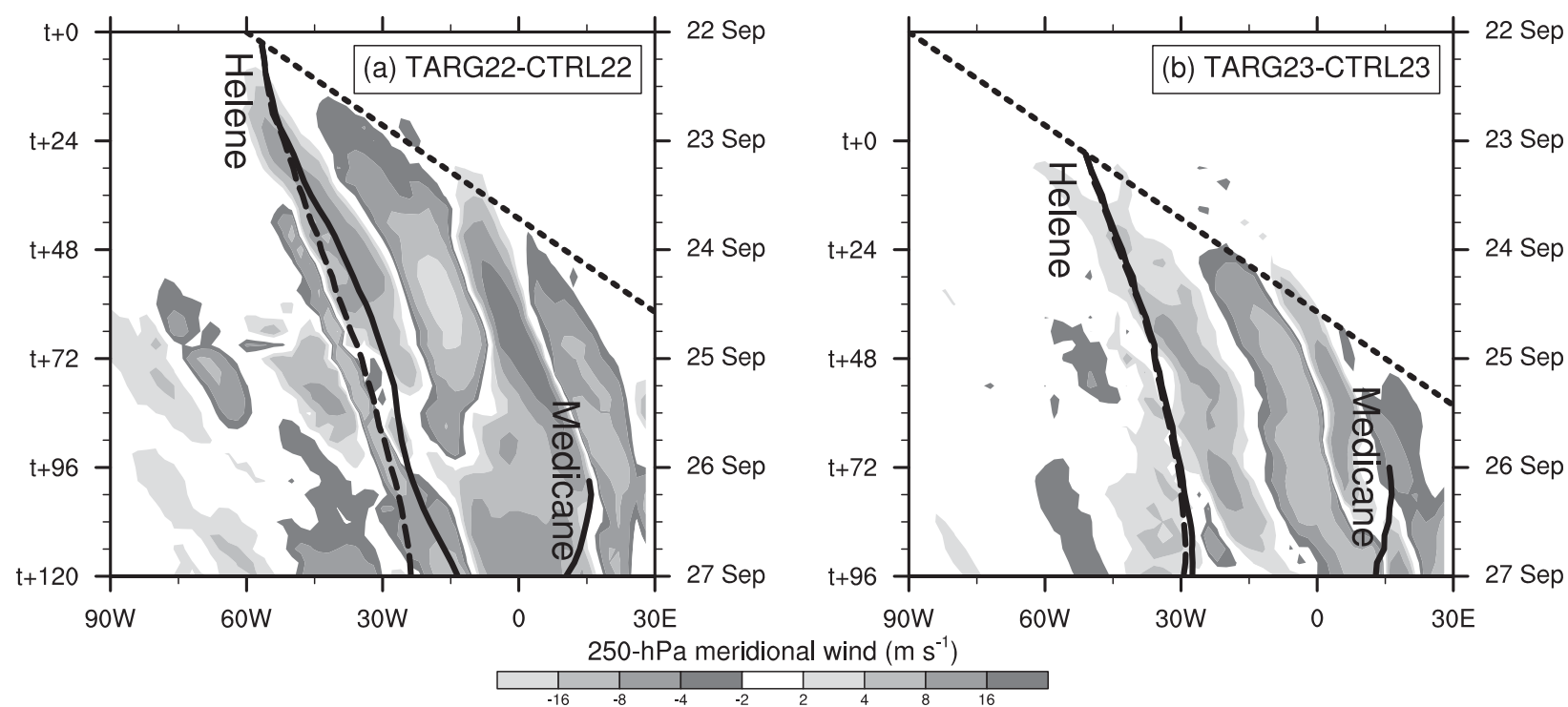

FIG. 14. Time-longitude (Hovmöller) plots of the difference in the 250-hPa meridional wind (shading, in $\mathrm{m} \mathrm{s}^{-1}$ ) between Méso-NH targeted experiments TARG22 and TARG23 and control experiments CTRL22 and CTRL23, respectively. Position of Helene in the control (dashed curves) and targeted experiments (solid curves) and of the Medicane in the targeted experiments (solid curves). The dotted line represents a zonal speed of $35^{\circ}$ day $^{-1}$. 
times. The Medicane still developed in 8, 5, and 5 members at 60-, 84-, and 108-h lead time, respectively. Such a persistent probability at different initialization times is low but sufficient to alert a forecaster. It shows the advantage of an ensemble forecast over a single deterministic forecast to predict the possibility of a highimpact weather event.

The predictability of the Medicane in the ECMWF EPS was constrained by the forecast of the ET of Helene. This result confirms a suggestion of Chaboureau et al. (2012) based on deterministic forecasts. All EPS members from 84-, 108-, 132-, and 156-h lead time were partitioned in two clusters with an ascending hierarchical classification. They were partitioned after their potential temperature on the dynamical tropopause over western Europe at 1200 UTC 26 September. In the first cluster, in conformance with the analysis, the synoptic conditions were characterized by a trough-ridge-trough pattern, typical of an ET (Anwender et al. 2008). The track of Helene was correctly forecast in most of the members, with a position error at 1200 UTC 26 September smaller than $1200 \mathrm{~km}$ for about $80 \%$ of all lead times. An elongated trough over the Mediterranean allowed 9 out of 102 members to develop a Medicane. In the second cluster, the synoptic conditions were dominated by a large low centered on the British Isles. A wrong southward bifurcation in the track of Helene was forecast in most of the members, with a position error at 1200 UTC 26 September larger than $1200 \mathrm{~km}$ for more than $90 \%$ of most lead times. In the absence of the elongated trough over the Mediterranean, only 1 out of 98 members developed a Medicane.

The two clusters offered two different scenarios for the ET of Helene, which were found at all initialization times. The partition in two scenarios was related to the phasing between Helene and an upstream trough. Perturbations in the initial MSLP enhanced the phasing when they accelerated Helene, in conformance with a previous study (Harr et al. 2008). Only a successful phasing in cluster 1 steered Helene northeastward and resulted in the building of a downstream ridge. In contrast, Helene was delayed and the downstream ridge underestimated in cluster 2 . Both the delay and the underestimation of the downstream ridge increased with the lead time. Differences between clusters quickly propagated downstream with the group speed of a Rossby wave train. They reached the downstream trough at the end of ET, which elongated toward the Mediterranean in cluster 1 only. Uncertainties in the ET after 24 September, including a late southward bifurcation of Helene, did not reach the Mediterranean before the development of the Medicane. All EPS members at 36- and 60-h lead time were initialized after the crucial phasing of Helene with the upstream trough. Though many of them did not forecast the Medicane, they all predicted correct synoptic conditions over the Mediterranean and were classified in cluster 1 . The correct scenario in cluster 1 was quasi necessary, but not sufficient, for the development of the Medicane.

Méso-NH simulations initialized from perturbed conditions further showed the dynamical linkage between the ET of Helene and the Medicane. Perturbations were selected from the ECMWF ensemble members at 108- and 84-h lead time that predicted the development of the Medicane and showed the best position of Helene at 1200 UTC 26 September. Only targeted perturbations at 0000 UTC 22 and 23 September on Helene and the upstream trough were sufficient in developing the Medicane with a warm core, an extended PV tower, and a minimum MSLP of 993 and $989 \mathrm{hPa}$, respectively. In the targeted experiment initialized at 0000 UTC 22 September, Helene was accelerated and the upstream trough broke earlier, while the building of the downstream ridge was overestimated with respect to the analysis. This overestimation allowed the downstream trough to elongate toward the Mediterranean rather than merge with the upstream trough as in the control forecast. In this case, initial perturbations were apparently exaggerated but compensated for model errors in the dynamics of the downstream trough. In the targeted experiment initialized at 0000 UTC 23 September, the downstream ridge had a correct meridional extent, which also allowed the downstream trough to elongate toward the Mediterranean. In contrast, perturbations applied at 0000 UTC 22 and 23 September on the complementary domain did not improve the control forecast, which missed the development of the Medicane.

This study confirms the sensitivity of an ET to the initial conditions of both the cyclone and an upstream trough that has been found recently for some case studies (Reynolds et al. 2009; Anwender et al. 2010; Lang et al. 2012). A strong impact of initial perturbations on both the track of Helene and its midlatitude environment emphasized the crucial phasing of the cyclone with an upstream trough (Klein et al. 2002; Grams et al. 2013). This impact quickly propagated toward the Mediterranean with a Rossby wave train, as in idealized (Riemer and Jones 2010) and real-case studies (Grams et al. 2011). The synoptic conditions over the Mediterranean were therefore characterized by a low predictability, which is typical downstream of an ET event (Harr et al. 2008; Anwender et al. 2008; Keller et al. 2011). Targeted observations on the cyclone and the upstream trough could increase the predictability of both the cyclone and the downstream flow, as suggested 
by previous studies (e.g., Torn 2010). Further work is needed to investigate other sources of uncertainty and understand the sufficient conditions for the forecast of the Medicane. To the author's knowledge, the ability of an EPS to forecast a high-impact downstream weather event was revealed for the first time in this challenging context. This result extends the potential utility of an EPS for high-impact weather (Buizza and Hollingsworth 2002; Buizza and Chessa 2002) to the prediction of a mesoscale storm downstream of an ET event. Investigation of other case studies is needed to generalize this result.

Acknowledgments. We thank Jim Doyle and Carolyn Reynolds for an idea that led to the present study, Doris Anwender for suggestions to analyze ensemble forecasts, and the whole team led by Sarah Jones for helpful discussions and for their welcome during a research stay of the first author at the Karlsruhe Institute of Technology. Constructive remarks and detailed suggestions from two anonymous reviewers substantially improved the manuscript. This study was sponsored by the Institut National des Sciences de l'Univers through the EPIGONE project. The first author was supported by a CNRS and Météo-France Ph.D. grant. Computer resources were allocated by GENCI (Project 90569). ECMWF data were downloaded from the MARS server and globally merged IR brightness temperature data from the NASA Mirador website.

\section{REFERENCES}

Anwender, D., P. A. Harr, and S. C. Jones, 2008: Predictability associated with the downstream impacts of the extratropical transition of tropical cyclones: Case studies. Mon. Wea. Rev., 136, 3226-3247.

— S. C. Jones, M. Leutbecher, and P. A. Harr, 2010: Sensitivity experiments for ensemble forecasts of the extratropical transition of typhoon Tokage (2004). Quart. J. Roy. Meteor. Soc., 136 (646A), 183-200, doi:10.1002/qj.527.

Bechtold, P., E. Bazile, F. Guichard, P. Mascart, and E. Richard, 2001: A mass flux convection scheme for regional and global models. Quart. J. Roy. Meteor. Soc., 127, 869-886.

Belamari, S., 2005: Report on uncertainty estimates of an optimal bulk formulation for surface turbulent fluxes. MERSEA IP Deliverable, D.4.1.2, 29 pp.

Buizza, R. and P. Chessa, 2002: Prediction of the U. S. storm of 24-26 January 2000 with the ECMWF Ensemble Prediction System. Mon. Wea. Rev., 130, 1531-1551.

— and A. Hollingsworth, 2002: Storm prediction over Europe using the ECMWF ensemble prediction system. Meteor. Appl., 9 (3), 289-305, doi:10.1017/S1350482702003031.

Chaboureau, J.-P., and P. Bechtold, 2005: Statistical representation of clouds in a regional model and the impact on the diurnal cycle of convection during Tropical Convection, Cirrus and Nitrogen Oxides (TROCCINOX). J. Geophys. Res., 110, D17103, doi:10.1029/2004JD005645.
— , and C. Claud, 2006: Satellite-based climatology of Mediterranean cloud systems and their association with large-scale circulation. J. Geophys. Res., 111, D01102, doi:10.1029/ 2005JD006460.

—, F. Pantillon, D. Lambert, E. Richard, and C. Claud, 2012: Tropical transition of a Mediterranean storm by jet crossing. Quart. J. Roy. Meteor. Soc., 138, 596-611.

Cuxart, J., P. Bougeault, and J.-L. Redelsperger, 2000: A turbulence scheme allowing for mesoscale and large-eddy simulations. Quart. J. Roy. Meteor. Soc., 126, 1-30.

Dirren, S., M. Didone, and H. Davies, 2003: Diagnosis of "forecastanalysis" differences of a weather prediction system. Geophys. Res. Lett., 30, 2060, doi:10.1029/2003GL017986.

Grams, C. M., and Coauthors, 2011: The key role of diabatic processes in modifying the upper-tropospheric wave guide: A North Atlantic case-study. Quart. J. Roy. Meteor. Soc., 137 (661), 2174-2193.

_ S. C. Jones, and C. Davis, 2013: The impact of Typhoon Jangmi (2008) on the midlatitude flow. Part II: Downstream evolution. Quart. J. Roy. Meteor. Soc., doi:10.1002/qj.2119, in press.

Harr, P. A., and R. Elsberry, 2000: Extratropical transition of tropical cyclones over the western North Pacific. Part I: Evolution of structural characteristics during the transition process. Mon. Wea. Rev., 128, 2613-2633.

— D. Anwender, and S. C. Jones, 2008: Predictability associated with the downstream impacts of the extratropical transition of tropical cyclones: Methodology and a case study of Typhoon Nabi (2005). Mon. Wea. Rev., 136, 3205-3225.

Jones, S. C., and Coauthors, 2003: The extratropical transition of tropical cyclones: Forecast challenges, current understanding, and future directions. Wea. Forecasting, 18, 1052-1092.

Keller, J. H., S. C. Jones, J. L. Evans, and P. A. Harr, 2011: Characteristics of the TIGGE multimodel ensemble prediction system in representing forecast variability associated with extratropical transition. Geophys. Res. Lett., 38, L12802, doi:10.1029/2011GL047275.

Klein, P., P. Harr, and R. Elsberry, 2002: Extratropical transition of western North Pacific tropical cyclones: Midlatitude and tropical cyclone contributions to reintensification. Mon. Wea. Rev., 130, 2240-2259.

Lafore, J.-P., and Coauthors, 1998: The Meso-NH Atmospheric Simulation System. Part I: adiabatic formulation and control simulations: Scientific objectives and experimental design. Ann. Geophys., 16, 90-109.

Lang, S. T. K., S. C. Jones, M. Leutbecher, M. S. Peng, and C. A. Reynolds, 2012: Sensitivity, structure, and dynamics of singular vectors associated with Hurricane Helene (2006). J. Atmos. Sci., 69, 675-694.

Leutbecher, M., and T. N. Palmer, 2008: Ensemble forecasting. J. Comput. Phys., 227 (7), 3515-3539, doi:10.1016/ j.jcp.2007.02.014.

Martius, O., C. Schwierz, and H. C. Davies, 2008: Far-upstream precursors of heavy precipitation events on the Alpine southside. Quart. J. Roy. Meteor. Soc., 134, 417-428.

Moscatello, A., M. M. Miglietta, and R. Rotunno, 2008a: Numerical analysis of a Mediterranean "hurricane" over southeastern Italy. Mon. Wea. Rev., 136, 4373-4397.

$\longrightarrow, \ldots$, and $\longrightarrow, 2008 \mathrm{~b}$ : Observational analysis of a Mediterranean "hurricane" over southeastern Italy. Weather, 63, 306-311.

Pantillon, F., J.-P. Chaboureau, P. Mascart, and C. Lac, 2013: On the role of a Rossby wave train during the extratropical transition of Hurricane Helene (2006). Quart. J. Roy. Meteor. Soc., 139 (671), 370-386, doi:10.1002/qj.1974. 
Pergaud, J., V. Masson, S. Malardel, and F. Couvreux, 2009: A parameterization of dry thermals and shallow cumuli for mesoscale numerical weather prediction. Bound.-Layer Meteor., 132, 83-106.

Pinty, J.-P., and P. Jabouille, 1998: A mixed-phase cloud parameterization for use in a mesoscale non-hydrostatic model: Simulations of a squall line and of orographic precipitations. Preprints, Conf. on Cloud Physics, Everett, WA, Amer. Meteor. Soc., 217-220.

Reynolds, C. A., M. S. Peng, and J.-H. Chen, 2009: Recurving tropical cyclones: Singular vector sensitivity and downstream impacts. Mon. Wea. Rev., 137, 1320-1337.

Riemer, M., and S. C. Jones, 2010: Downstream impact of tropical cyclones on a developing baroclinic wave in idealized scenarios of extratropical transition. Quart. J. Roy. Meteor. Soc., 136, 617-637.

Saunders, R., M. Matricardi, P. Brunel, S. English, P. Bauer, U. O'Keeffe, P. Francis, and P. Rayer, 2005: RTTOV-8 Science and validation report. Tech. Rep., NWP SAF Rep., $41 \mathrm{pp}$.

Torn, R. D., 2010: Diagnosis of the downstream ridging associated with extratropical transition using short-term ensemble forecasts. J. Atmos. Sci., 67, 817-833.

, and G. J. Hakim, 2009: Initial condition sensitivity of western Pacific extratropical transitions determined using ensemble-based sensitivity analysis. Mon. Wea. Rev., 137, 3388-3406. 